Article

\title{
Experimental Study on Punching Performance of Recycled Aggregate Concrete Thin Wallboard with Single-Layer Reinforcement
}

\author{
Wenchao Liu ${ }^{1,2}$, Wanlin Cao ${ }^{2, *}$, Nana Zong ${ }^{3}$, Ruwei Wang ${ }^{2}$ and Lele Ren ${ }^{2}$ \\ 1 Office of Postdoctoral Research, Beijing University of Technology, Beijing 100124, China; liuwenchao@bjut.edu.cn \\ 2 College of Architecture and Civil Engineering, Beijing University of Technology, Beijing 100124, China; \\ wangruwei@bjut.edu.cn (R.W.); renlele@bjut.edu.cn (L.R.) \\ 3 Beijing Urban Construction Design \& Development Group Co. Limited, Beijing 100034, China; \\ zongnana@bjucd.com \\ * Correspondence: wlcao@bjut.edu.cn; Tel.: +86-10-6739-2819
}

Received: 19 December 2017; Accepted: 18 January 2018; Published: 26 January 2018

\begin{abstract}
Recycle Aggregate Concrete (RAC) is a common "green" product used for a variety of purposes, although the durability and strength of the material still need more research to adequately determine influences on these parameters. The failure pattern, punching bearing capacity, and deflection variation of wallboard of both ordinary concrete and RAC with various rebar reinforcement diameters and spacing were analyzed. Based on experimental data, the ABAQUS finite element analysis of the thin wallboard was performed, and the calculated results are in good agreement with the experimental results. The results show that the failure characteristics of ordinary concrete wallboards and RAC wallboards are similar, but the brittleness of the RAC specimens is more significant. Under the same reinforcement ratio, concrete material, whether new or recycled, had little effect on the punching bearing capacity of the specimens. In the case of a low reinforcement ratio, increasing the reinforcement ratio (decreasing the spacing of steel bars) can effectively improve the bearing capacity of the wallboard. Under the same reinforcement ratio, the wallboard with larger diameter and larger spacing has a higher bearing capacity and less deformation after failure.
\end{abstract}

Keywords: recycle aggregate concrete; thin wallboard with single-layer reinforcement; punching bearing capacity; experimental research; simulation

\section{Introduction}

Accompanied by the continuous development of material science, as well as the continuous improvement of environmental awareness [1-4], recycled aggregate concrete (RAC) has been widely received by the majority of scientific and technical personnel in the field of construction for various uses. RAC is made of recycled concrete aggregate (RCA) that comes from repurposed construction waste. Preliminary exploration of recycled concrete began in the 1940s (Glushge [5], 1946), and currently, many scholars study the mix design method, aggregate types, and fundamental mechanical properties of RAC. Bairagi [6] and Kwan [7] systematically studied the mix design method/procedure of RCA. Their results show that a suitable concrete mix design enables RAC to the achieve target strength. It also outlines the mix design parameters. The properties of concrete containing recycled fine aggregate were investigated by Khatib [8]. Their results show that the strength of recycled concrete is reduced when the replacement ratio of recycled fine aggregate reaches $15 \sim 30 \%$. Ravindrarajah [9] and Tam [10] studied the elastic modulus and strength of recycled aggregate concrete. Their results show that the strength and elastic modulus of recycled aggregate concrete are reduced by about $10 \%$ and $35 \%$, respectively. These studies are important for studying the mechanical properties of recycled aggregate concrete, especially to understand the essential parameters for determining the deflection as well as cracking of a RAC structure. 
The flexural properties of recycled coarse concrete beams were previously studied by Dosho [11] and Knaack [12], who showed that the bearing capacity of recycled concrete beams is not different from that of ordinary concrete beams, although the deformation and crack width are slightly larger than those of ordinary concrete beams. The shear behavior of recycled coarse concrete beams was tested by Han $[13,14]$ and González-Fonteboa [15]. The results show that the deformation and oblique crack propagation of recycled concrete beams with the same concrete strength are essentially the same as those of made of ordinary concrete, but the shear capacity is smaller. With the increase of the replacement ratio of the recycled coarse aggregate, the shear strength of the recycled concrete beams tends to decrease. Andrzej [16] and Xiao et al. [17] conducted experiments on the compressive properties of recycled coarse and fine aggregate concrete columns. The recycled reinforced concrete columns had the same failure mode as that of ordinary reinforced concrete columns. The bearing capacity of recycled reinforced concrete columns decreases with the increase of recycled aggregate replacement ratio, but the amplitude is not large. Konno [18] studied the mechanical properties of recycled aggregate concrete columns filled with steel tubes, showing that the mechanical properties of recycled aggregate concrete confined with steel tubes are similar to those consisting of ordinary concrete columns and have good ductility. However, the former shows a decrease in both stiffness and bearing capacity, which decreases with the increase of the replacement ratio of recycled aggregates. This is mainly due to the lower strength of RAC compared to ordinary concrete. Seismic performance tests of low, medium, and high shear walls of recycled coarse and fine aggregate concrete were performed by Cao and Zhang [19-23], showing that the bearing capacity, stiffness, ductility, and energy dissipation capacity of recycled coarse aggregate concrete shear walls are slightly worse than those of ordinary concrete shear walls. Again, with the increase of recycled aggregate replacement in the mixture, the bearing capacity and ductility of the recycled aggregate concrete shear wall decreases, although the seismic performance of the recycled concrete shear walls does meet the needs of structural design.

The punching performance of ordinary concrete slabs has been thoroughly determined, either through experimental analysis or modeling. Talbot [24] used experiments to determine the formula of the punching shear bearing capacity of ordinary concrete. Elstner [25] furthered this work by refining the punching shear bearing capacity on 39 6-ft square column slabs. Zheng [26] continued to perform theoretical analysis and experimental research on the punching capacity of ordinary concrete. However, the research on the punching properties of recycled aggregate concrete slab is not yet sufficient, and the previous studies [27-30] mainly focused on thicker members (the slabs with double row reinforcement, as shown in Figure 1a). So far, there is no report about the punching performance of recycled aggregate concrete thin wallboard with a single-layer of reinforcement (Figure 1b), which is more environmentally and economically friendly compared to thicker concrete slabs with extra reinforcement. Therefore, it is necessary to study the punching performance of this type of thin wallboard.

In this paper, a total of 12 sets of single-row reinforced RAC wallboard units were designed and tested. The influence of concrete material type, reinforcement ratio (reinforcement spacing), and reinforcement form on the failure modes, bearing capacity, and deflection of single-layer reinforced concrete wallboard were studied. Based on the experimental data, an ABAQUS finite element analysis of the thin wallboards was carried out, which provides a data reference for the practical application of these RAC thin wallboards.

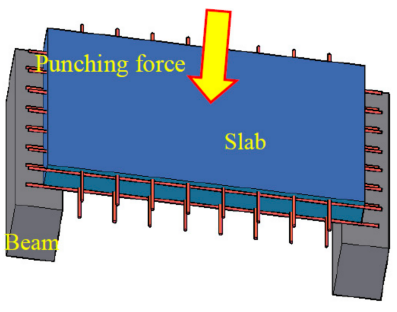

(a)

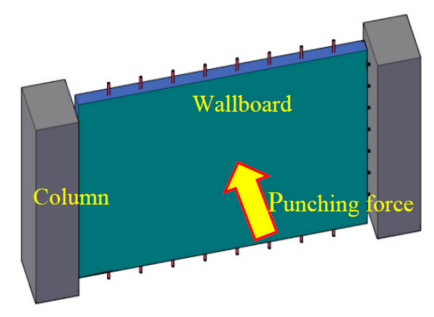

(b)

Figure 1. Punching stress state of different components. (a) Floor slabs with double row reinforcement; (b) Thin wallboard with single-layer reinforcement. 


\section{Tests and Methods}

\subsection{Test Parameters}

The main parameters of the specimens that were varied include the concrete material type, reinforcement ratio (steel spacing) and steel bar diameter. The concrete materials were divided into two types: (1) ordinary fine aggregate concrete (FAC) and (2) semi-recycled aggregate concrete with recycled coarse aggregate replacing $100 \%$ of the aggregates. The size of coarse aggregate for the above two types of concrete materials was $5-10 \mathrm{~mm}$, and the size of fine aggregate was 0-5 mm. Recycled aggregates were processed by Beijing Shougang Co., Ltd. (Beijing, China). Figure 2 shows a photograph of the processing of the construction waste (referring to the waste generated by man-made or natural causes in construction, including waste residue soil, abandoned soil, silt, and discarded material, etc.) to create the recycled coarse aggregate, and the necessary parameters of the recycled coarse aggregate were in line with standard GB/T 25177-2010 [31]. Figure 3 shows the particle size distribution curve of the coarse aggregates in the RCA. The particle size distribution of normal aggregates was 5-25 mm. The proportion of ordinary concrete and recycled aggregate concrete is shown in Table 1, and the strength grade of the concrete was C40 (determined by the calculation of the standard value of the cube compressive strength.). The experimental parameters of the specimens are shown in Table 2.

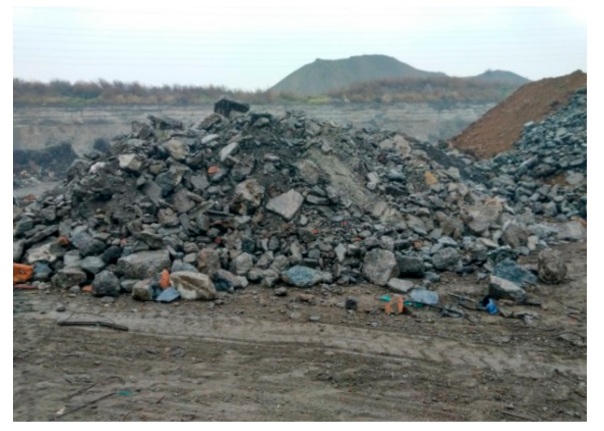

(a)

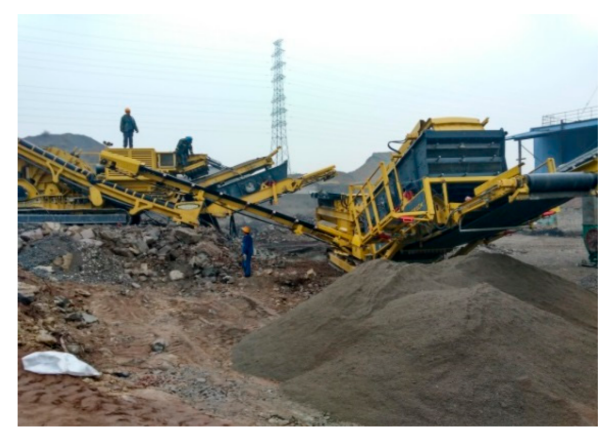

(b)

Figure 2. The processing of recycled concrete aggregate (RCA). (a) The construction waste; (b) The recycled concrete aggregate.

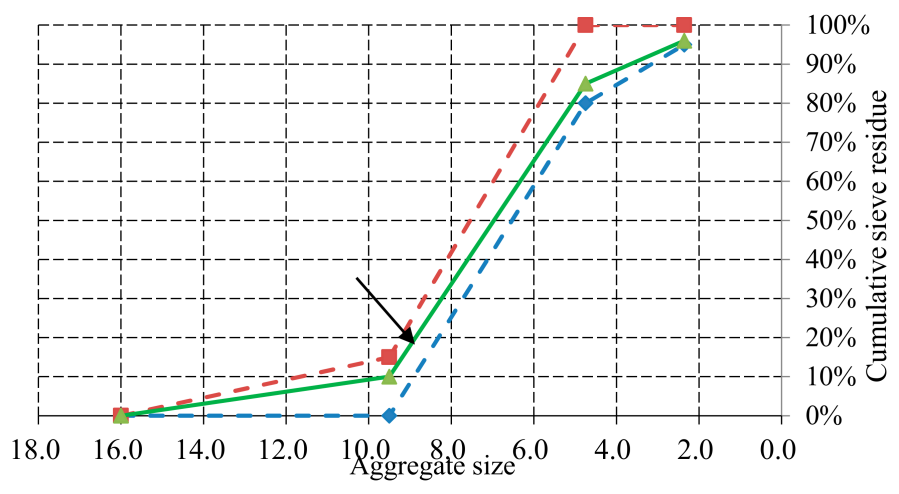

Figure 3. Aggregate gradation of coarse aggregate in RCA.

Table 1. Proportion of ordinary concrete and recycled aggregate concrete.

\begin{tabular}{ccccccc}
\hline \multicolumn{7}{c}{ Mix Proportion of the Concrete kg/m } \\
\hline Cement & Fly Ash & Mineral Powder & Sand & $\begin{array}{l}\text { Ordinary-Pebble/ } \\
\text { Recycled-Pebble }\end{array}$ & Water & Water Reducer \\
\hline 369 & 79 & 79 & 841 & 841 & 181 & 3.5 \\
\hline
\end{tabular}


Table 2. Parameters of specimens.

\begin{tabular}{|c|c|c|c|c|c|c|}
\hline No. & $D / m m$ & $S / m m$ & $W / m m$ & $L / m m$ & $T / m m$ & Concrete Types \\
\hline BD5-40-1 & 5 & \multirow{2}{*}{50} & \multirow{12}{*}{600} & \multirow{12}{*}{600} & \multirow{12}{*}{40} & \multirow{6}{*}{ RAC } \\
\hline BD4-40-1 & 4 & & & & & \\
\hline BD5-40-2 & 5 & \multirow{2}{*}{75} & & & & \\
\hline BD4-40-2 & 4 & & & & & \\
\hline BD5-40-3 & 5 & \multirow{2}{*}{100} & & & & \\
\hline BD4-40-3 & 4 & & & & & \\
\hline PD5-40-1 & 5 & & & & & \multirow{6}{*}{ FAC } \\
\hline PD4-40-1 & 4 & 50 & & & & \\
\hline PD5-40-2 & 5 & \multirow{2}{*}{75} & & & & \\
\hline PD4-40-2 & 4 & & & & & \\
\hline PD5-40-3 & 5 & \multirow{2}{*}{100} & & & & \\
\hline PD4-40-3 & 4 & & & & & \\
\hline
\end{tabular}

P: FAC sample; B: RAC sample; D: rebar diameter; S: reinforcement spacing; W: width (mm); L: length (mm); T: thickness (mm).

Specimens were designed for ease of assembly, with $4 \mathrm{~mm}$ thick steel plates used for the external skeleton (bolt holes can be reserved), and then high strength steel bars (D4/D5) were welded on the external steel plates to form a framework of steel reinforcement, as shown in Figure 4.

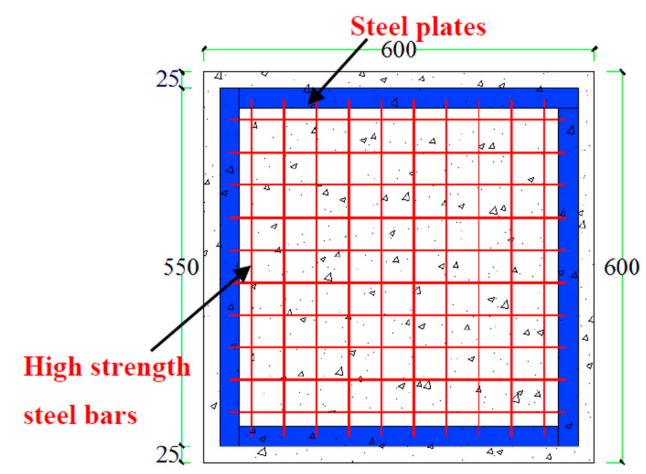

(a)

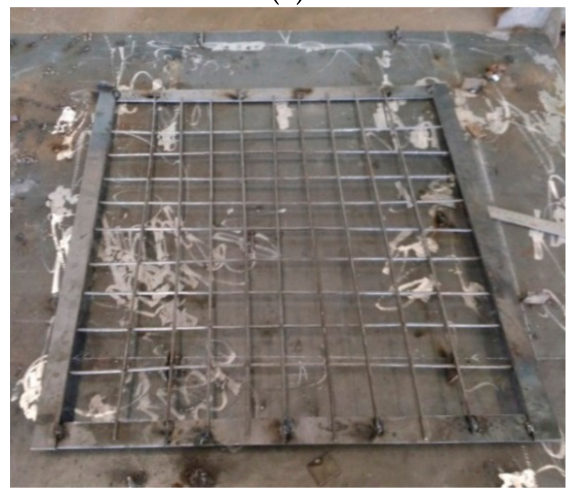

(b)

Figure 4. Detailed information of the steel skeleton of the specimen. (a) Sketch of reinforcement; (b) Detailed photograph of steel skeleton.

\subsection{Material Properties}

According to the Chinese standard GB/T 228-2002 [32], the steel bars and steel plates were subjected to the metal tensile test, taking measurements three times for each base metal to obtain the mean value of the yield strength and ultimate strength. The results are shown in Table 3. 
Table 3. Test results of steel plate and steel bars.

\begin{tabular}{cccc}
\hline Base Metal type & Yield Strength $f_{\mathbf{y}} / \mathbf{M P a}$ & Ultimate Strength $f_{\mathbf{u}} / \mathbf{M P a}$ & Elastic Modulus $E / \mathbf{M P a}$ \\
\hline D4 rebar & 721 & 906 & $2.10 \times 10^{5}$ \\
\hline D5 rebar & 697 & 801 & $2.09 \times 10^{5}$ \\
\hline 4 mm steel plate & 315 & 467 & $2.18 \times 10^{5}$ \\
\hline
\end{tabular}

The standard cube compressive strength test was performed on three standard concrete cubes for each type of cement (FAC and RAC; $100 \mathrm{~mm}$ sides with adjustment coefficient of 0.95 [33]). The average compressive strength of the three sample cubes was obtained as shown in Table 4. The coefficient of variation (standard deviation/average mean) was less than $10 \%$. The tensile strength test of concrete requires a highly precise test instrument. In this paper, the tensile strengths of FAC and RAC were calculated based on the reference [34].

Table 4. Test results of cube compressive strength of fine aggregate concrete (FAC) and RAC concrete cube samples.

\begin{tabular}{cccc}
\hline Concrete Types & Strength Grade of Concrete & Cube Compressive Strength & Elastic Modulus \\
\hline FAC & C40/40.00 MPa & $40.10 \mathrm{MPa}$ & $32,958 \mathrm{MPa}$ \\
\hline RAC & C $40 / 40.00 \mathrm{MPa}$ & $41.15 \mathrm{MPa}$ & $30,283 \mathrm{MPa}$ \\
\hline
\end{tabular}

\subsection{Test Set-Up and Loading}

Testing was performed in the Mechanical Engineering Laboratory of the Beijing University of Technology. A hydraulic universal testing machine WE-20 was used with a maximum tonnage of $20 \mathrm{t}$. In order to apply even force across the sample, the vertical concentrated force was distributed to the four steel loading columns, which are spaced $200 \mathrm{~mm}$ apart. Also, four supporting columns were used to support the sample. A total of eight electrical dial indicators were used to record the deflection of the specimen during loading. The maximum deflection of the center of the wallboard was calculated from data from the $1 \#$ and $2 \#$ dial indicators; the $7 \#$ and $8 \#$ dial indicators were used to record the mid-span deflection of the specimens; the 3-6\# dial indicators were used to record the corner deflection of the specimens. The specific layout of the measuring points is shown in Figure 5. Before formal loading, the specimen was pre-loaded for calibration, which was a maximum of $10 \%$ of the ultimate load calculated by the test piece. At the beginning of loading, $10 \%$ of the ultimate load was applied. When the specimen enters the yielding stage, $7 \%(1 / 15)$ of the ultimate load was applied until the specimen was destroyed.

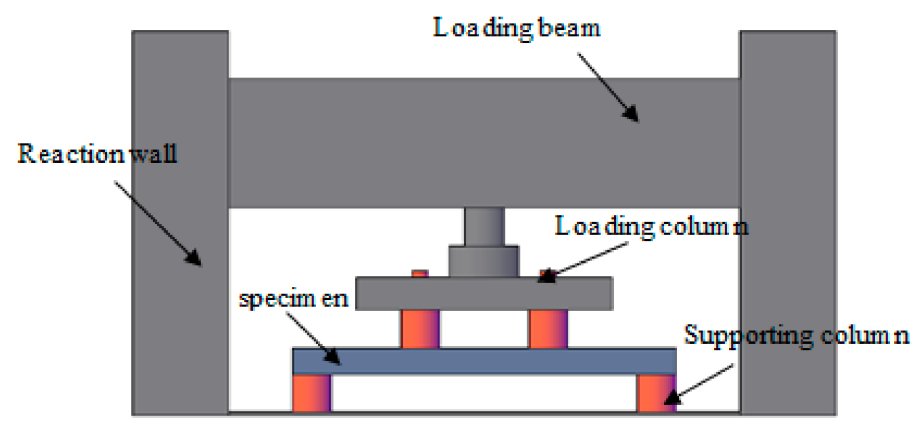

(a)

Figure 5. Cont. 


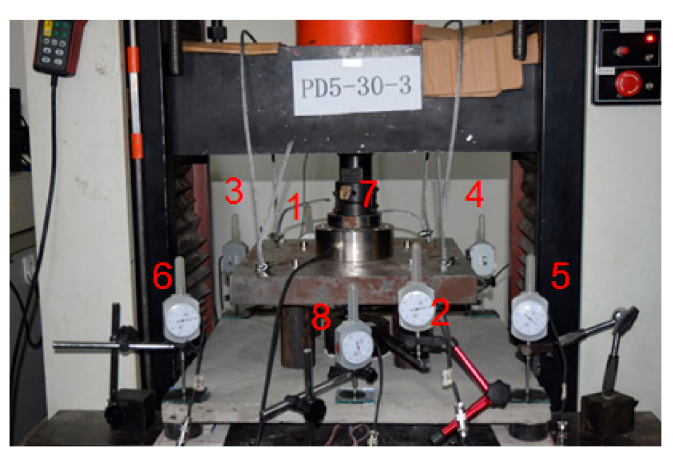

(b)

Figure 5. Loading device and arrangement of measuring points. (a) Loading sketch map; (b) Loading field.

\section{Results and Discussion}

\subsection{Failure Characteristics}

During the initial stage of loading, the concrete of the wallboard was not cracked, and the specimen was in an elastic stage. As the load increased, tiny cracks began to appear at the bottom surface of the specimens, especially the corresponding positions of the four loading columns. With the continued applied force, the developed cracks start to connect along the loading column and radial cracks perpendicular to the edge of the specimens developed. To about $0.8 F_{\mathbf{u}}$ (punching ultimate load), annular surface cracks formed largely on the top surface of the wallboard, but due to the incomplete development of a "plastic hinge." bending failure did not occur at this stage. When the load increased to the specimens' punching ultimate load $F_{\mathrm{u}}$, with an obvious crackling noise, the specimen could not continue to withstand the load and was damaged by punching. The characteristic point load obtained from the tests are shown in Table 5

Table 5. Test results of wallboard.

\begin{tabular}{cccc}
\hline NO. & $\boldsymbol{F}_{\mathbf{c}} / \mathbf{k N}$ & $\boldsymbol{F}_{\mathbf{y}} / \mathbf{k N}$ & $\boldsymbol{F}_{\mathbf{u}} / \mathbf{k N}$ \\
\hline BD4-40-1 & 4.4 & 23.9 & 25.2 \\
BD4-40-2 & 3.8 & 18.4 & 20.2 \\
BD4-40-3 & 3.1 & 14.4 & 16.0 \\
PD4-40-1 & 4.7 & 25.8 & 26.3 \\
PD4-40-2 & 4.0 & 20.8 & 23.1 \\
PD4-40-3 & 3.5 & 15.4 & 16.8 \\
BD5-40-1 & 5.4 & 30.1 & 31.7 \\
BD5-40-2 & 4.7 & 25.3 & 27.8 \\
BD5-40-3 & 4.0 & 20.9 & 23.3 \\
PD5-40-1 & 5.7 & 30.2 & 31.8 \\
PD5-40-2 & 5.3 & 27.0 & 29.7 \\
PD5-40-3 & 4.4 & 21.9 & 24.3
\end{tabular}

$F_{\mathrm{c}}$ : cracking load; $\overline{F_{\mathrm{y}}: \text { yield load calculated by the energy method; }} F_{\mathrm{u}}$ : ultimate load.

The normal aggregate concrete specimens and recycled coarse concrete specimens had similar punching shear failure modes (based on the experimental observation, a partial bending deformation is considered), but crack development was different in the different samples. In the compressive area of the ordinary concrete specimens, the cracks were more fully developed, indicating that the integrity of the recycled aggregate concrete specimens was relatively low when the specimens were punched and destroyed. The damage forms of RAC specimen (BD4-40-1, BD4-40-2, and BD4-40-3) and ordinary FAC specimen (PD4-40-1, PD4-40-2, and PD4-40-3) are shown in Figures 6 and 7. The deformation of the normal aggregate concrete specimens was more symmetrical when destroyed, so the deformability of the recycled coarse aggregate concrete specimens is relatively low. Moreover, it can be seen that the specimen with smaller spacing has better deformation ability when the concrete material type is the same. 


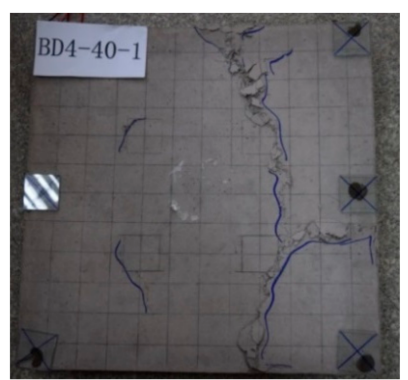

(a)

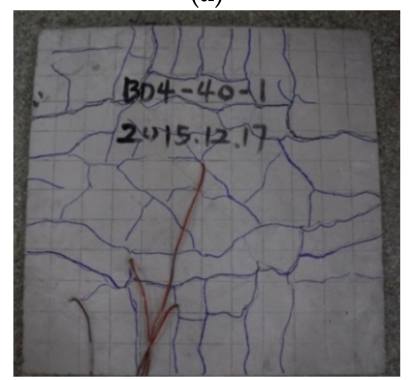

(d)

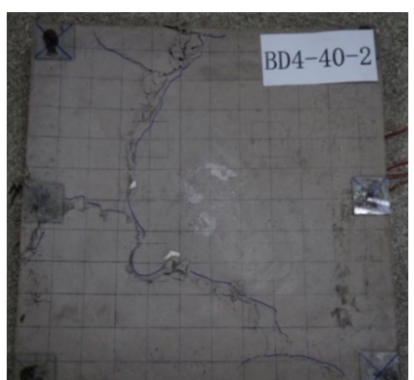

(b)

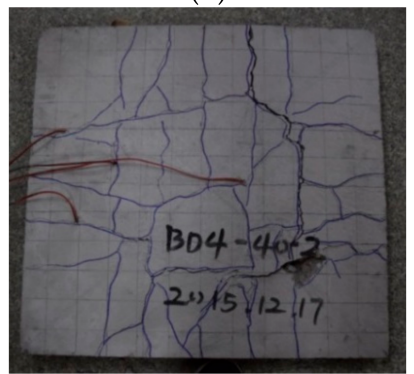

(e)

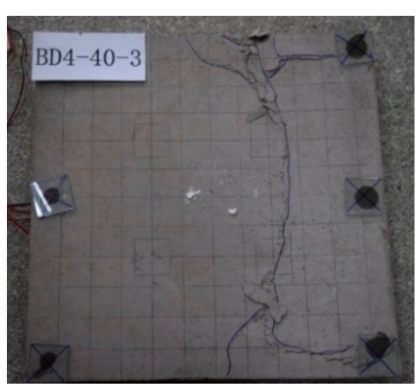

(c)

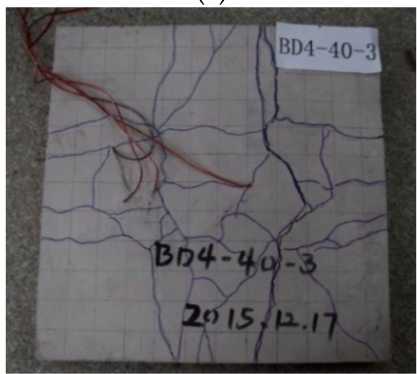

(f)

Figure 6. Failure modes of recycled concrete wallboard. (a) BD4-40-1 (top surface); (b) BD4-40-2 (top surface); (c) BD4-40-3 (top surface); (d) BD4-40-1 (bottom surface); (e) BD4-40-2 (bottom surface); (f) BD4-40-3 (bottom surface).

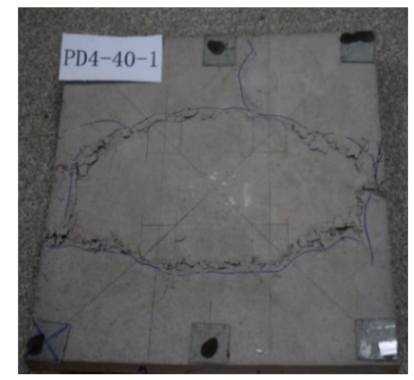

(a)

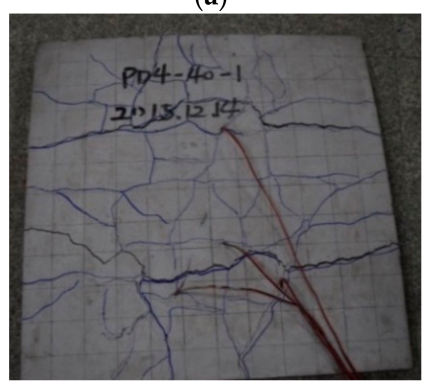

(d)

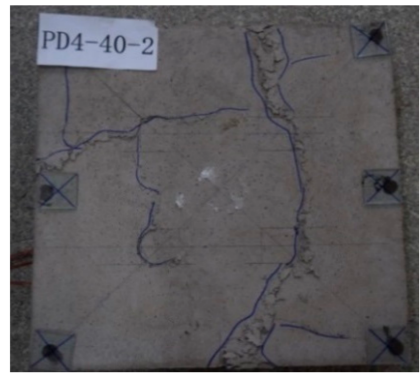

(b)

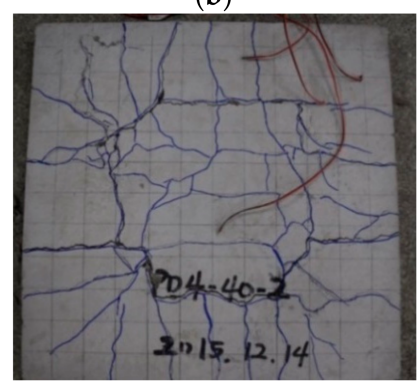

(e)

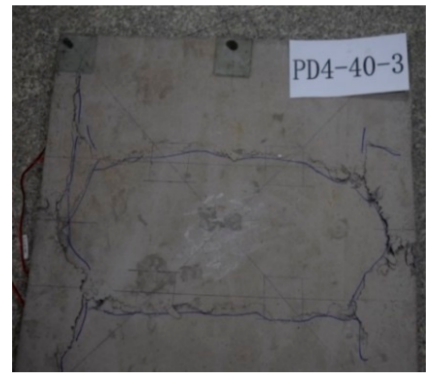

(c)

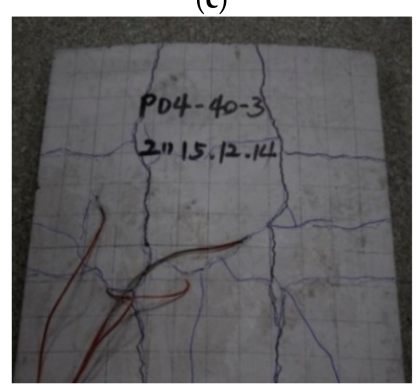

(f)

Figure 7. Failure modes of ordinary concrete wallboard. (a) PD4-40-1 (top surface); (b) PD4-40-2 (top surface); (c) PD4-40-3 (top surface); (d) PD4-40-1 (bottom surface); (e) PD4-40-2(bottom surface); (f) PD4-40-3 (bottom surface).

\subsection{Load-Bearing Capacity}

The load-displacement (F- $\Delta$ ) curve of the specimen reflects the performance of the plate in terms of bearing capacity. Displacement refers to the vertical displacement of the loading column. The influence of concrete material, reinforcement ratio (bar spacing), and steel structure form on the punching and cutting bearing capacity of the specimen are shown in Figures 8-10. 


\subsubsection{Influences of Concrete Material Type}

In Figure 8, $\Delta$ is the displacement of the loading beam, and the $\mathrm{F}$ is the vertical load. The difference between the ultimate bearing capacity of ordinary concrete wallboard and recycled aggregate concrete wallboard can be calculated by $\mathrm{DV}_{\mathrm{F}}=\left(\mathrm{F}_{\mathrm{FRA}}-\mathrm{F}_{\mathrm{RCA}}\right) / \mathrm{F}_{\mathrm{FRA}} * 100 \%$, and the difference of the average ultimate bearing capacity was $\mathrm{MDV}_{\mathrm{F}}=5.8 \%$. The specific results of the $\mathrm{DV}_{\mathrm{F}}$ are shown in Figure $8 \mathrm{a}$ to Figure $8 \mathrm{f}$. The bearing capacity of ordinary concrete wallboard was slightly higher than that of recycled concrete wallboard, so the concrete material had little effect on the bearing capacity of wallboard.

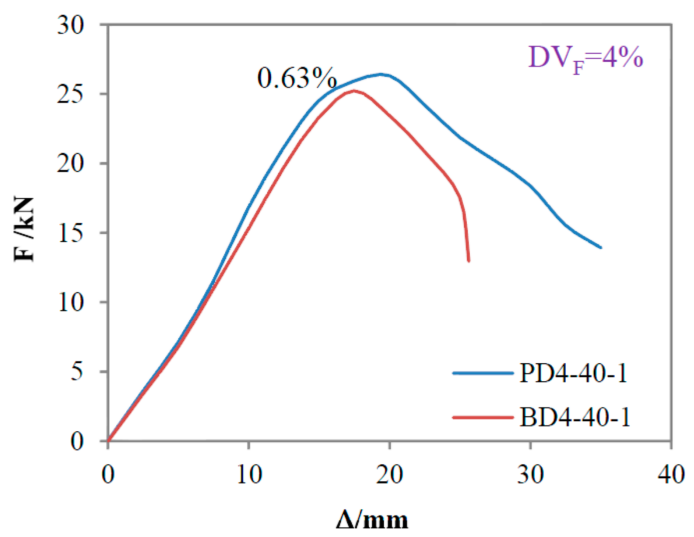

(a)

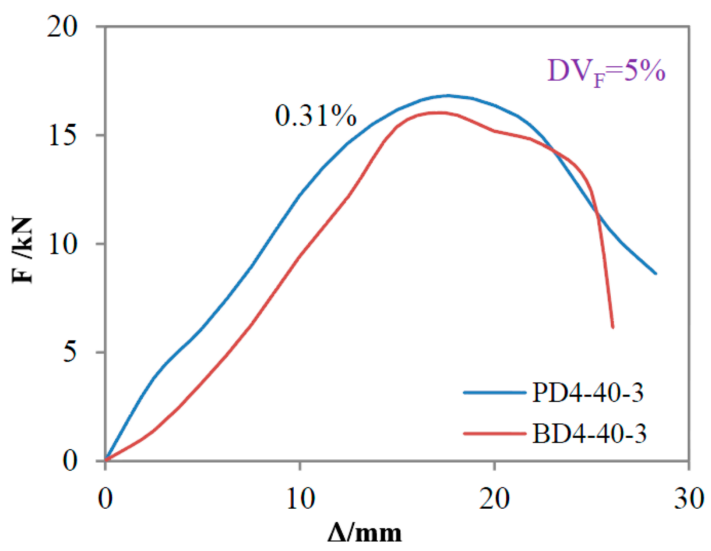

(c)

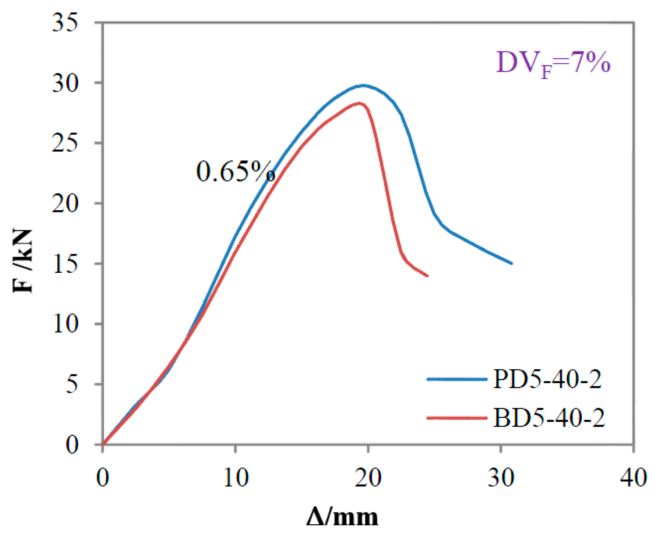

(e)

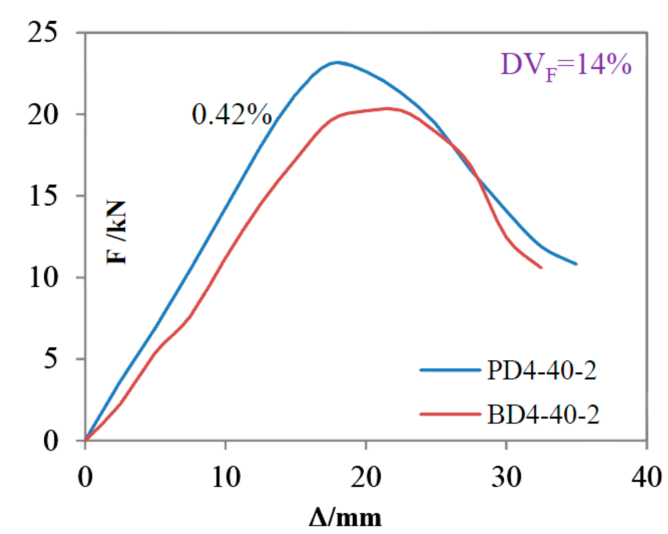

(b)

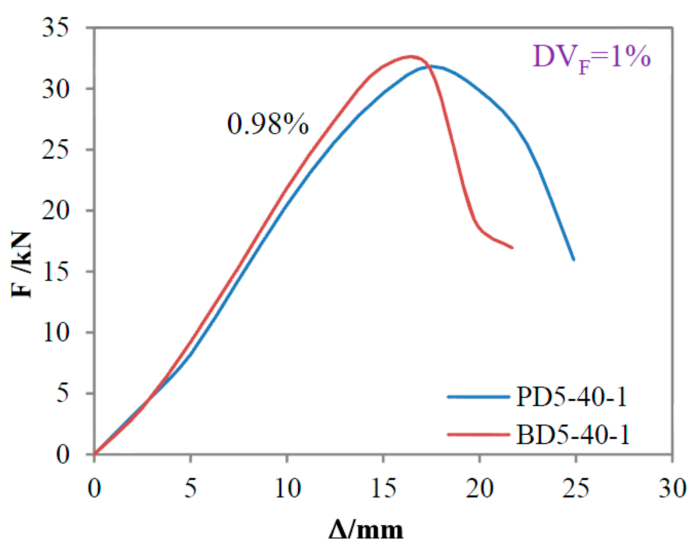

(d)

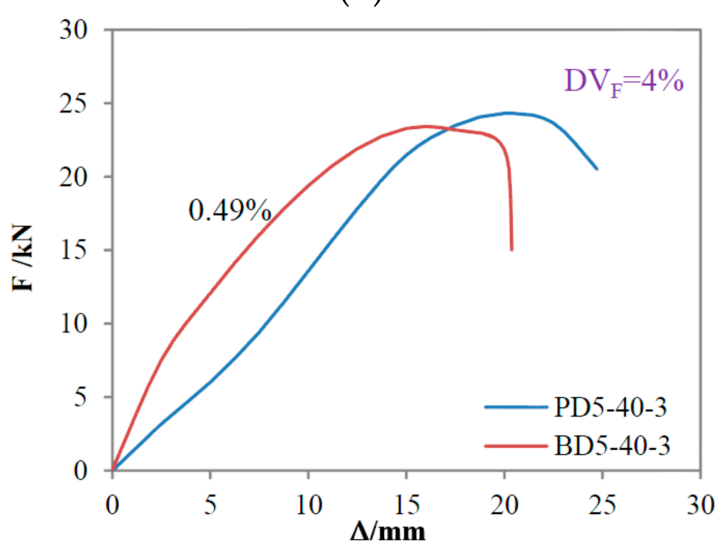

(f)

Figure 8. Influence of concrete material on bearing capacity of specimens. (a) Reinforcement ratio of $0.63 \%$; (b) Reinforcement ratio of $0.42 \%$; (c) Reinforcement ratio of $0.31 \%$; (d) Reinforcement ratio of $0.98 \%$; (e) Reinforcement ratio of $0.65 \%$; (f) Reinforcement ratio of $0.49 \%$. 


\subsubsection{Influences of Reinforcement Ratio (Reinforcement Spacing)}

As shown in Figure 9, the bearing capacity of the wallboard decreased with the decrease of reinforcement ratio (the bearing capacity decreased with the increase of the reinforcement spacing) Therefore, in the case of a relatively low reinforcement ratio $(0.31-0.63 \%)$, increasing the reinforcement ratio can effectively improve the bearing capacity of the wallboard. The specimen with a larger bar diameter will also have a greater bearing capacity, although the bearing capacity decreases more quickly at later failure stages. Compared with ordinary FAC wallboard (Figure 9a,b), the bearing capacity of RAC wallboard decreased faster during the last stage of failure (Figure 9c,d).

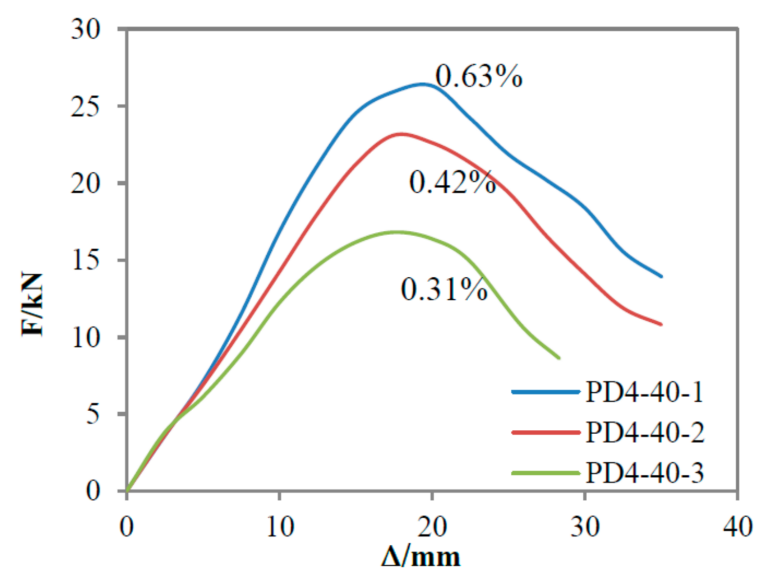

(a)

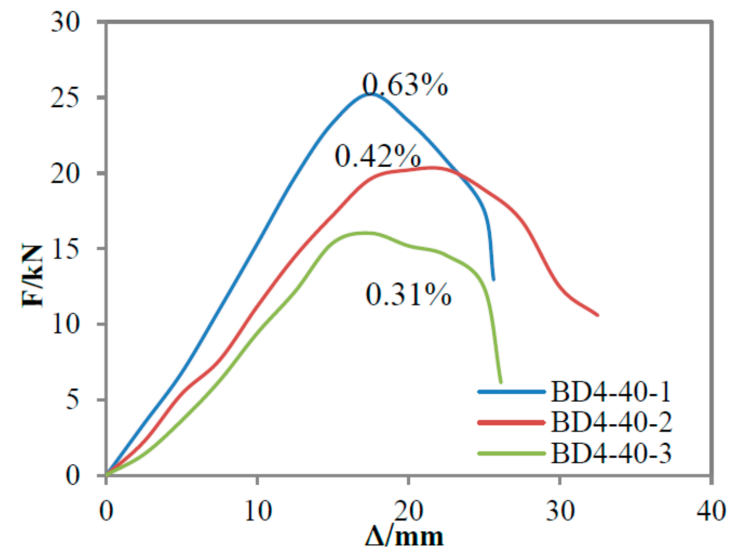

(c)

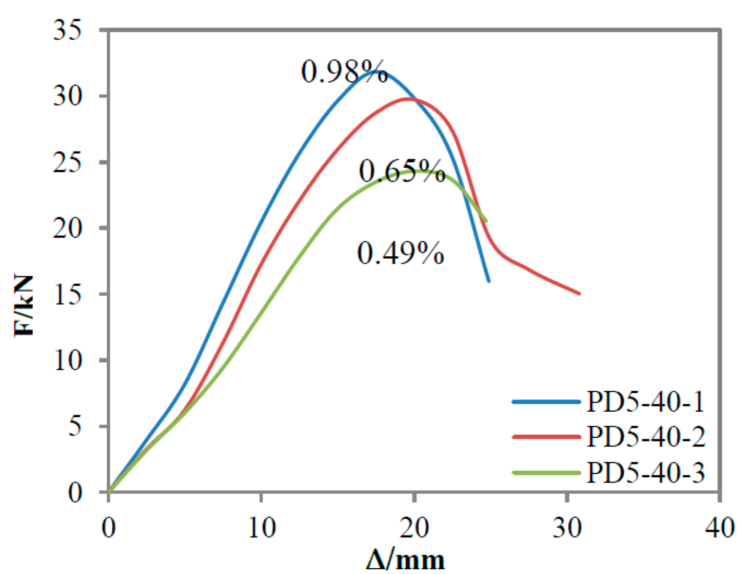

(b)

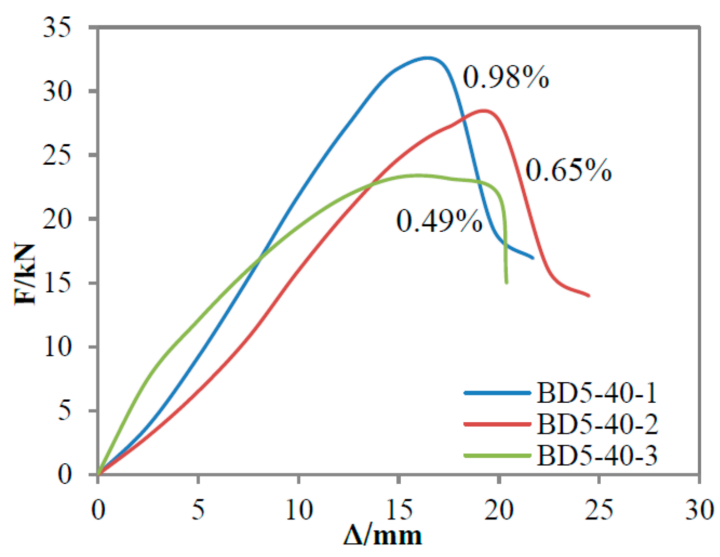

(d)

Figure 9. Influence of reinforcement ratio on the bearing capacity of specimens. (a) Ordinary concrete wallboard with $\mathrm{D}=4$; (b) Ordinary concrete wallboard with $\mathrm{D}=5$; (c) Recycled concrete wallboard with $\mathrm{D}=4 ;$ (d) Recycled concrete wallboard with $\mathrm{D}=5$.

\subsubsection{Influences of Reinforced Form}

Different combinations of reinforcing bar spacing and bar diameter can lead to different forms of reinforcement. So it is necessary to study the influence of the reinforcement form on the bearing capacity of the specimen under the same reinforcement ratio. As can be seen from Figure 10, under the same conditions of concrete materials, the bearing capacity of specimens with a larger steel bar and larger spacing was greater, but the bearing capacity decreased rapidly in the final stage. 


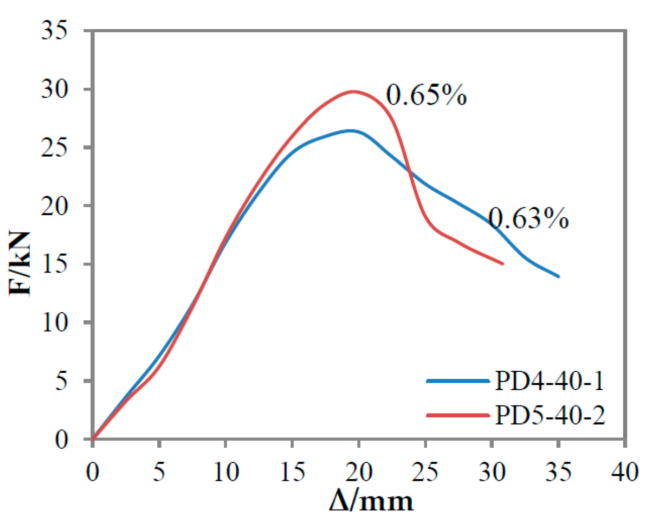

(a)

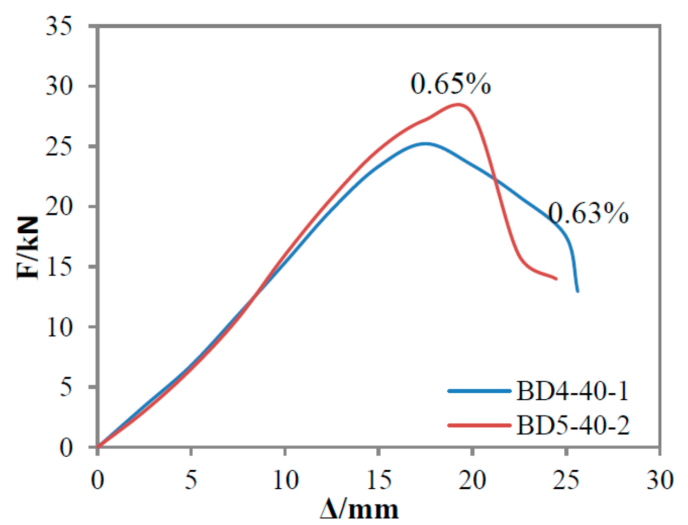

(b)

Figure 10. Influence of reinforcement ratio on bearing capacity of specimens. (a) Ordinary concrete wallboard with different reinforced form; (b) Recycled concrete wallboard with different reinforced form.

\subsection{Deflection Analysis}

Taking PD-40-1 as an example, the variation in deflection during the loading process was analyzed. The center deflection of the specimen was calculated by the measured results from the 1\# and 2\# dial indicators. The deflection of other measuring points 3 8\# can be measured directly. The load deflection F-U curve of the specimen PD-40-1 during loading process is shown in Figure 11a,b.

The center and mid-span of the wallboard were bent and deformed downward, and the maximum deflection of the center point was about $36 \mathrm{~mm}$. The deflection of the support point increased inversely with downward direction, indicating that the corner of the wallboard at the support point warped upward to a maximum of $4.5 \mathrm{~mm}$. In order to analyze the effects of the concrete material, reinforcement ratio and reinforcement form on the center deflection of the specimen, the load deflection F-U curve of specimen is given.

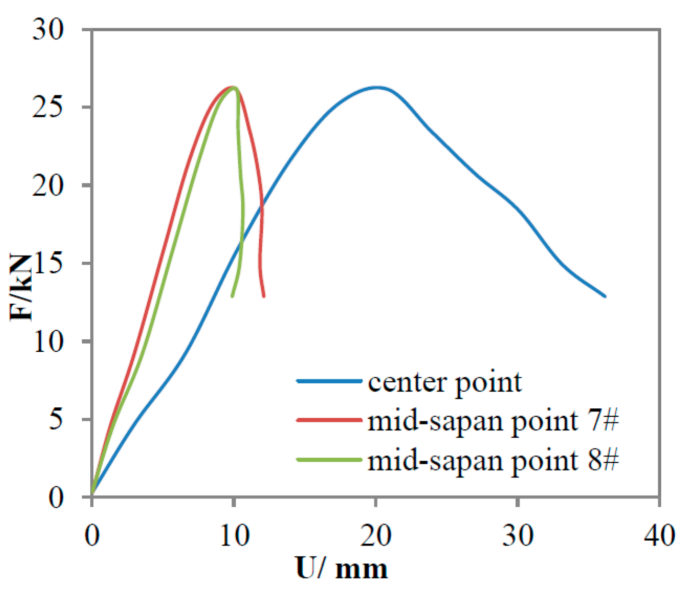

(a)

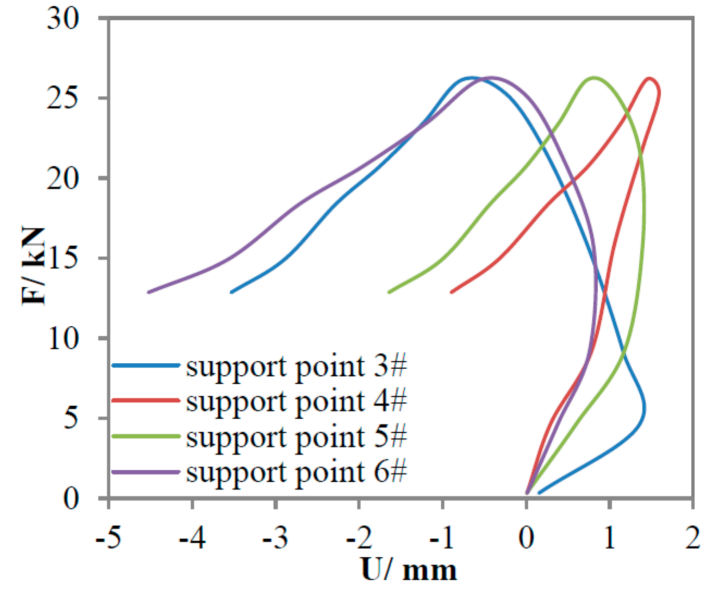

(b)

Figure 11. Load deflection F-U curve of specimen PD-40-1. (a) Deflection of the support point; (b) Deflection of the center and mid-span point.

Figure 12 show that the deflection values of ordinary FAC specimen was larger than the RAC specimen, therefore the deformation capacity of the FAC specimens was relatively stronger. The main reason is that the elastic modulus of the recycled aggregate concrete is lower than that of the FAC. The deformation capacity of specimens with a high reinforcement ratio is poor, which indicates that 
the reinforcement ratio of specimens in practical engineering should not be too high. In the case of equivalent reinforcement, the specimens with smaller bars and smaller spacing have better capacity to deform, rather than fail, under stress.

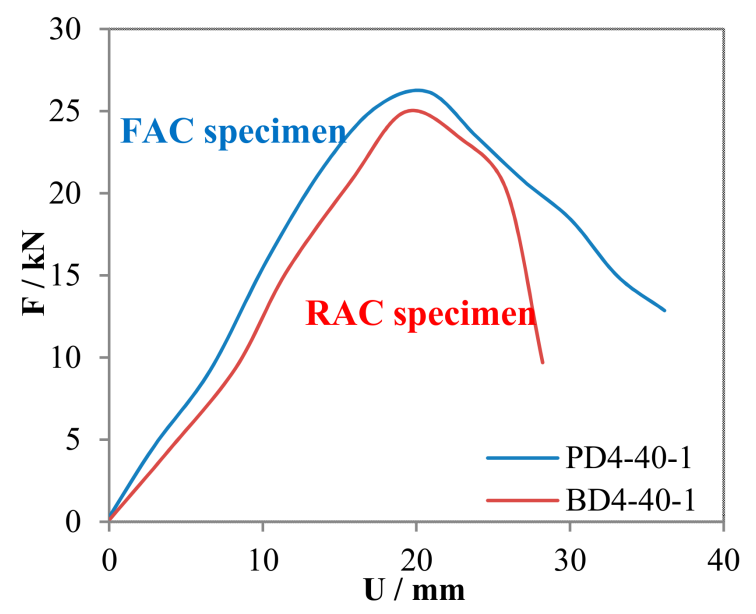

(a)

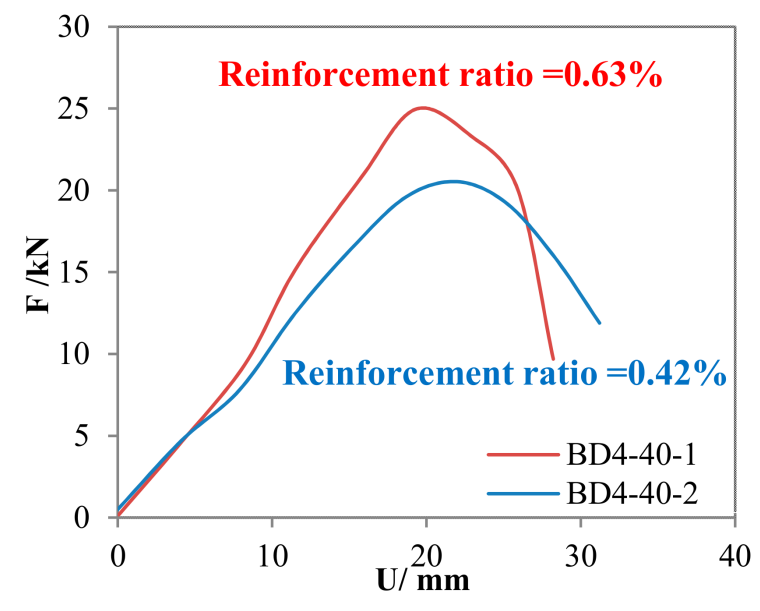

(b)

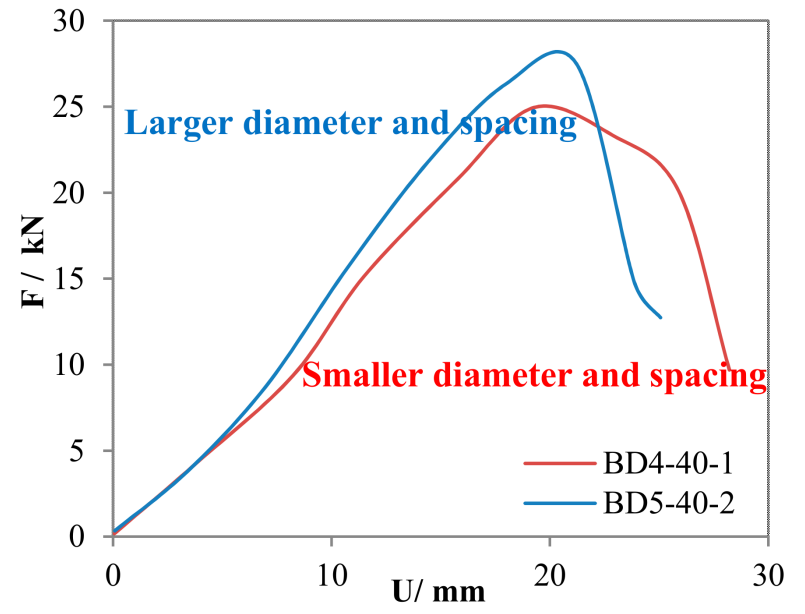

(c)

Figure 12. Effect of different parameters on the center deflection. (a) Effect of material types; (b) Effect of reinforcement ratio; (c) Effect of reinforcement form.

\section{Theoretical Calculation and Analysis}

Based on nonlinear finite element analysis theory, the finite element software ABAQUS (ABAQUS Inc., Pawtucket, RI, USA) was used to analyze the working mechanisms of a single row of reinforced recycled aggregate concrete thin wallboard. At the same time, the calculated load-deflection curve was compared to the measured curve to further analyze the damage and evolution of the structure.

\subsection{Material Constitutive Model}

\subsubsection{Recycled Aggregate Concrete}

There are three kinds of constitutive model of concrete commonly used in ABAQUS: concrete diffusion crack model, concrete brittle cracking model and concrete damage plastic model [35]. The concrete damage plastic model considers the effects of damage has on the material and can adequately simulate the behavior and response of concrete under monotonic loading. Therefore, in this paper, the plastic damage model was used to simulate the concrete. The fracture properties will not be taken into account in the model. 
(1) Tension and pressure injury

The plastic damage model for concrete in ABAQUS assumes that the concrete material is mainly subjected to tensile cracking and crushing. The yield and failure were respectively determined by equivalent tensile plastic strain $\widetilde{\varepsilon}_{t}^{p l}$ and equivalent compressive plastic strain $\widetilde{\varepsilon}_{c}^{p l}$. The tensile damage curve of concrete transforms the cracking strain into plastic damage strain by the destroying stress and cracking strain, while the compression damage curve of concrete was calculated by further transforming inelastic strain into plastic strain. The two formulas are shown in Equations (1) and (2).

$$
\begin{aligned}
& \widetilde{\varepsilon}_{t}^{p l}=\widetilde{\varepsilon}_{t}^{c k}-\frac{d_{t}}{\left(1-d_{t}\right)} \frac{\sigma_{t}}{E_{0}} \\
& \widetilde{\varepsilon}_{c}^{p l}=\widetilde{\varepsilon}_{c}^{i n}-\frac{d_{c}}{\left(1-d_{c}\right)} \frac{\sigma_{c}}{E_{0}}
\end{aligned}
$$

where $\widetilde{\varepsilon}_{t}^{c k}$ is the cracking tensile strain, $\widetilde{\varepsilon}_{t}^{c k}=\varepsilon_{t}-\varepsilon_{0 t}^{e l}, \varepsilon_{0 t}^{e l}=\sigma_{t} / E_{0}$, among them $\varepsilon_{0 t}^{e 1}$ is the elastic tensile strain of the non-destructive material, and $\varepsilon_{t}$ is the total tensile strain. $\widetilde{\varepsilon}_{c}^{i n}$ is the inelastic compression strain, where $\widetilde{\varepsilon}_{c}^{i n}=\varepsilon_{c}-\varepsilon_{0 c}^{e l}, \varepsilon_{0 c}^{e l}=\sigma_{c} / E_{0}$, among them $\varepsilon_{0 c}^{e 1}$ is the elastic compression strain of the non-destructive material, $\varepsilon_{c}$ is the total compression strain, $d_{t}$ is the tension damage variable, and $d_{c}$ is the compression damage variable.

(2) Uniaxial compressive and tensile stress-strain curves

In this paper, the compressive constitutive equation of RCA under uniaxial pressure proposed by Xiao [36] was used, as shown in Equation (3). Figure 13 shows the uniaxial compressive stress-strain curves of the recycled aggregate concrete.

$$
y= \begin{cases}a x+(3-2 a) x^{2}+(a-2) x^{3}, 0 \leq x<1 \\ \frac{x}{b(x-1)^{2}+x} & , x \geq 1\end{cases}
$$

where $x=\varepsilon / \varepsilon_{0}{ }^{\prime}, y=\sigma / f_{\mathrm{c}}{ }^{\prime} ; a$ is the coefficient at the ascending stage of the curve and $a=2.2\left(0.748 r^{2}-1.231 r+0.957\right)$, taken as $a=1.05$, among them $r$ is the recycled coarse aggregate replacement ratio, where $r=100 \%$. $b$ is the coefficient at the descending stage of the curve and $b=0.8(7.6483 \mathrm{r}+1.142)$, taken as $b=7.03$. The peak compressive strain of the recycled concrete prism is $\varepsilon^{\mathrm{r}} 0,1.2$ times the peak compressive strain of ordinary concrete, and $f_{\mathrm{c}}^{\mathrm{r}}$ is the compressive strength of the recycled concrete prism and taken as $f_{\mathrm{c}}^{\mathrm{r}}=0.67 f_{\mathrm{cu}}$, where $f_{\mathrm{cu}}$ is the measured value of the concrete cube compressive strength (Table 4).

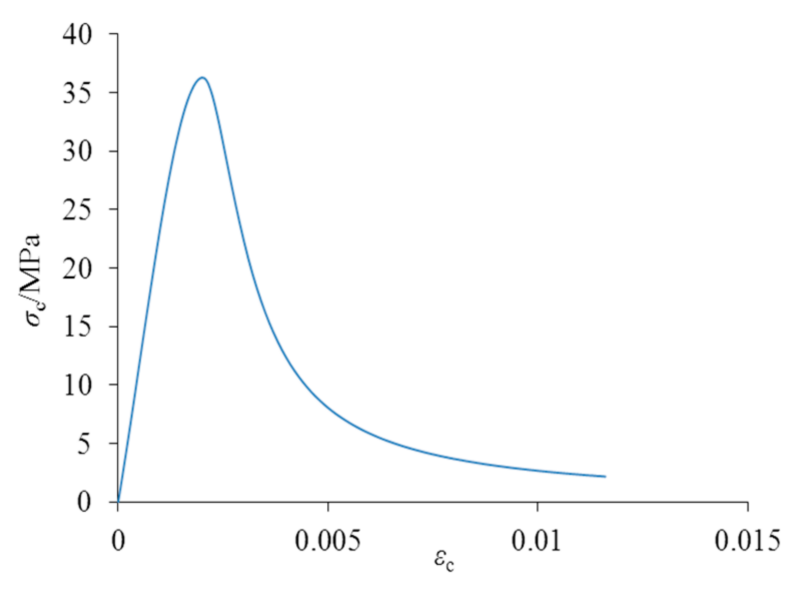

Figure 13. Compression stress-strain curve of recycled concrete. 
The model hypothesis of the tensile stress-strain principle is valid if the sample is without damage before reaching the peak stress. The descending curve can be calculated using Equation (4) [33].

$$
y=\frac{x}{\alpha_{t}(x-1)^{2}+x}, \quad x \geq 1
$$

where $x=\varepsilon / \varepsilon_{\mathrm{t} 0}^{\mathrm{r}}, y=\sigma / f_{\mathrm{t}}^{\mathrm{r}} ; \varepsilon_{\mathrm{t} 0}^{\mathrm{r}}$ is the peak tensile strain of the recycled concrete prism, $\varepsilon_{\mathrm{t} 0}^{\mathrm{r}}=f_{\mathrm{t}}^{\mathrm{r}} / E_{\mathrm{c}} ; f_{\mathrm{t}}^{\mathrm{r}}$ is the representative value of the uniaxial tension strength of concrete. $f_{\mathrm{t}}^{\mathrm{r}}=(-0.06 r+0.24)\left(f_{\mathrm{cu}}^{\mathrm{r}}\right)^{2 / 3}$, and $\alpha_{t}$ is the coefficient at the descending stage of the uniaxial tension stress-strain curve of concrete. The uniaxial tensile stress-strain curve of the recycled aggregate concrete is shown in Figure 14.

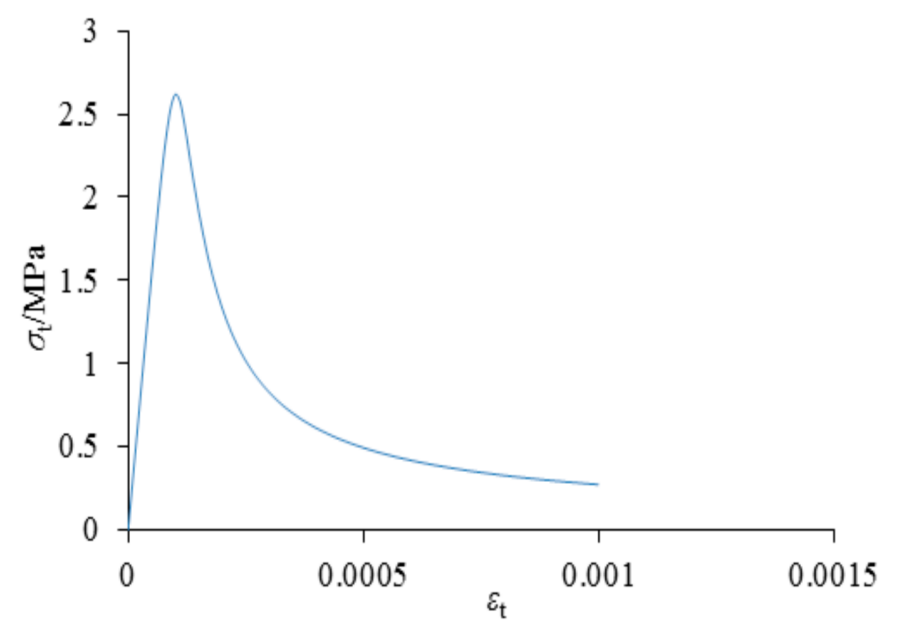

Figure 14. Tensile stress-strain curve of recycled concrete.

\subsubsection{Steel Rebar and Plate}

In this paper, the elasticity enhancement model (double line model) was used to simulate the reinforcement law. The Mises yield and kinematic hardening criteria were used in the numerical simulation. The stress-strain relationship of the steel bar was simplified as an oblique line. In this study, $E^{\prime} \mathrm{s}=0.01 E_{\mathrm{s}}$ [37], and Poisson's ratio was 0.3. Figure 15 shows the stress-strain curve of steel.

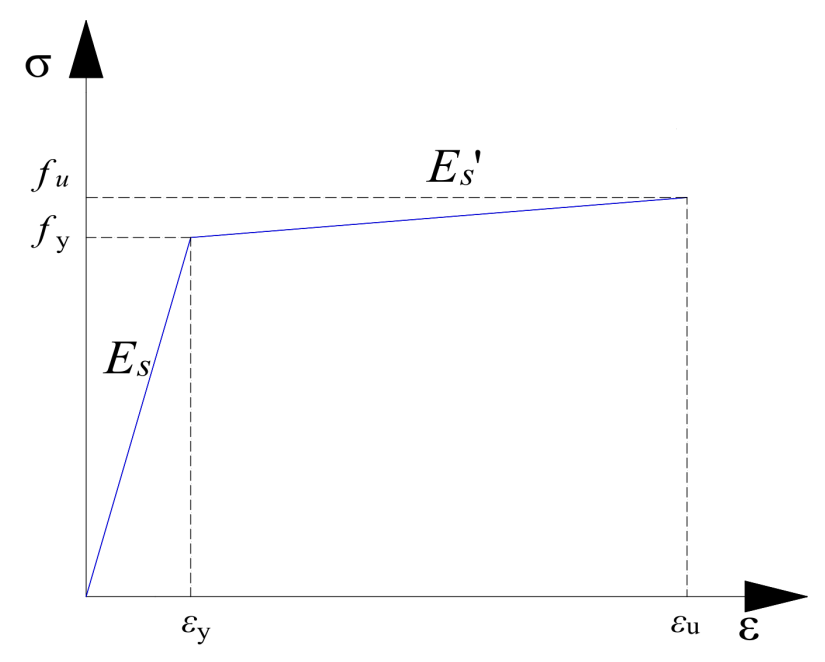

Figure 15. Stress-strain curve of steels. 
The true values of stress and strain were used in the ABAQUS software, while the nominal stress and nominal strain were measured in the material tensile test [38]. They can be converted by Equations (5) and (6).

$$
\begin{gathered}
\varepsilon=1 n\left(1+\varepsilon_{\text {nom }}\right) \\
\sigma=\sigma_{\text {nom }}\left(1+\varepsilon_{\text {nom }}\right)
\end{gathered}
$$

\subsubsection{Unit Selection}

The 3D solid element C3D8R was used to simulate the concrete and steel plates (columns). Also, the 3D truss element T3D2 was used for the rebar (the unit can only support axial loads and has three translational degrees of freedom at each node but no rotational degrees of freedom). During the modeling process, the steel bars and steel plates were merged into a steel skeleton and embedded in the concrete unit together, as shown in Figure 16.

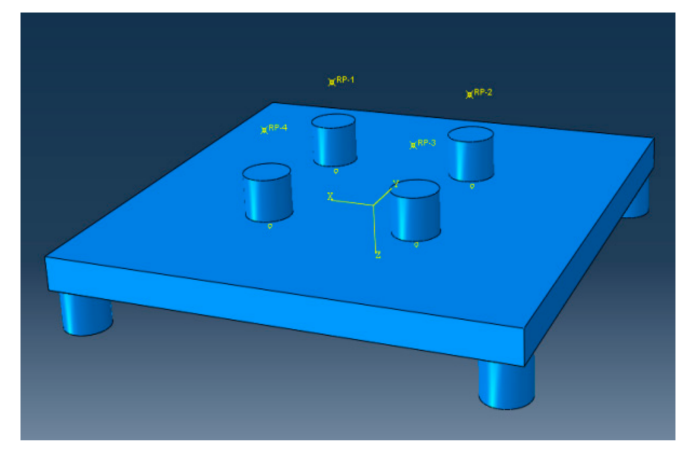

(a)

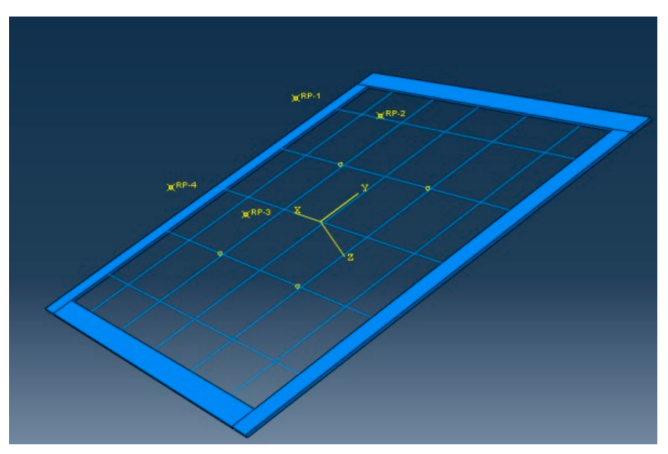

(b)

Figure 16. Finite element model. (a) Model parts; (b) Steel skeleton.

\subsection{Boundary Conditions and Meshing}

In order to have a consistent finite element model with the actual experiments, four loading columns and four supporting columns were defined. The bottom surfaces of the loading columns and the upper surface of the wallboard were defined as surface-to-surface contact interaction. The tangential behavior was Coulomb friction, with a coefficient of friction of 0.25 , and the normal behavior was set to "hard contact". Concurrently, the top surface of the supporting columns and the bottom surface of the wallboard were also defined as surface-surface contact interaction, as shown in Figure 17a. The bottom surfaces of the supporting columns were defined as a fixed constraint. Translational sliding of the test specimen in the unloaded direction during the loading process was constrained, as shown in Figure 17b. The model grid was divided by the green structure grid, as shown in Figure 18.

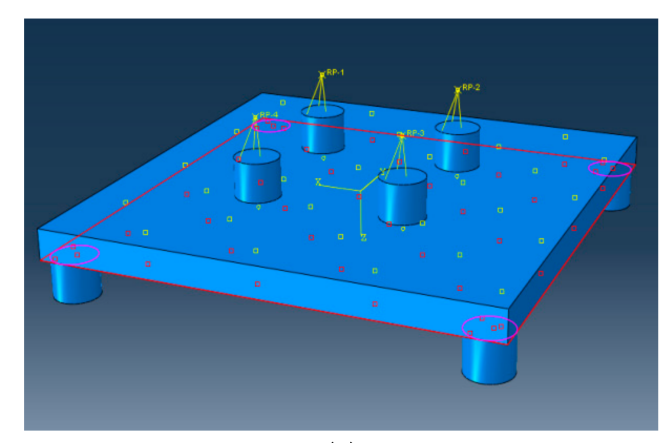

(a)

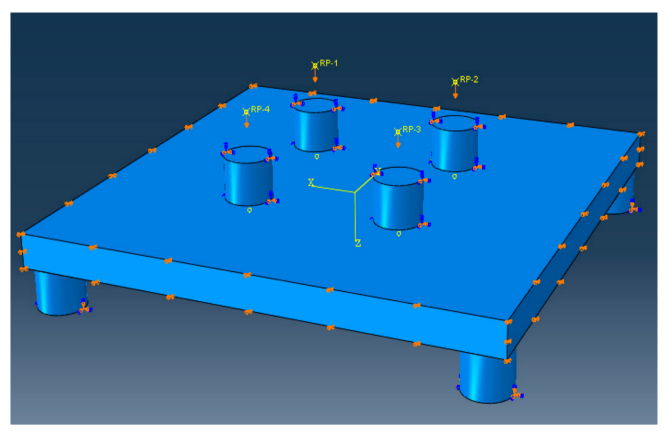

(b)

Figure 17. Boundary condition as defined. (a) Definition of contact relationships; (b) Applied constraints. 


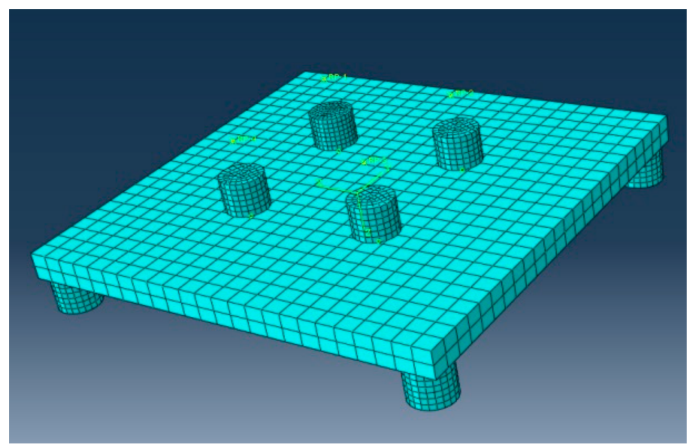

(a)

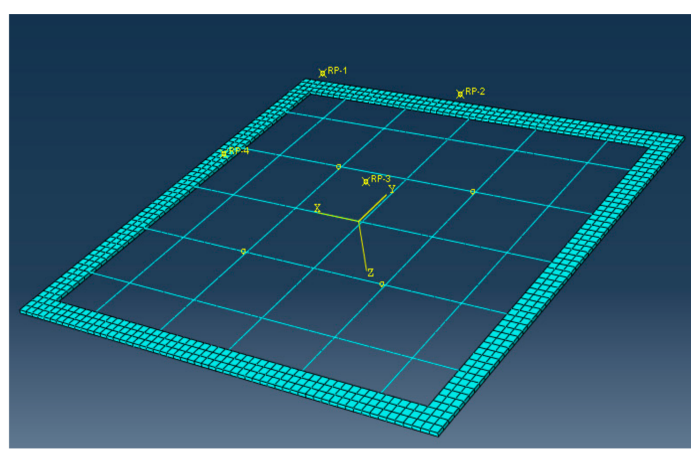

(b)

Figure 18. Mesh partition of modeled specimen. (a) Concrete meshing; (b) Steel skeleton meshing.

\subsection{Finite Element Calculation Results and Analysis}

\subsubsection{Comparative Analysis of Bearing Capacity}

Using specimens BD4-40-1, BD4-40-2, BD4-40-3, and PD4-40-3 as examples, the calculated and measured values of the ultimate load of each specimen are shown in Table $6 . F_{\mathrm{u}}^{\mathrm{c}}$ is the calculated value of the ultimate load in the table, and $F_{\mathrm{u}}^{\mathrm{e}}$ is the measured value of ultimate load. $\Delta F$ is the relative error between the calculated value of ultimate load and the measured value.

Table 6. Calculated and experimental results of ultimate load.

\begin{tabular}{cccccccc}
\hline No. & $\boldsymbol{F}_{\mathbf{u}}^{\mathrm{c}} / \mathbf{k N}$ & $\boldsymbol{F}_{\mathbf{u}}^{\mathrm{e}} / \mathbf{k N}$ & $\boldsymbol{\Delta} \boldsymbol{F}(\%)$ & No. & $\boldsymbol{F}_{\mathbf{u}}^{\mathrm{c}} / \mathbf{k N}$ & $\boldsymbol{F}_{\mathbf{u}}^{\mathbf{e}} / \mathbf{k N}$ & $\boldsymbol{\Delta} \boldsymbol{F ( \% )}$ \\
\hline BD4-40-1 & 26.16 & 25.23 & 3.69 & BD4-40-2 & 22.23 & 20.28 & 9.62 \\
\hline BD4-40-3 & 17.96 & 16.34 & 9.91 & PD4-40-3 & 17.78 & 16.80 & 5.83 \\
\hline
\end{tabular}

From Table 5, the relative error between the calculated value of the limit load and measured value was between $3.69 \%$ and $9.91 \%$, and the calculated results were slightly larger than the test results. Generally, the calculated results were in good agreement with the measured results.

\subsubsection{Comparison and Analysis of Load-Deflection Curve}

The calculated load-deflection curves and measured load-deflection curves of the center point of each specimen are shown in Figure 19.

When the load was lower than the ultimate load of the specimen, the slope of the calculated load-deflection curve was greater than the slope of the measured load-deflection curve. When the load exceeded the ultimate load of the specimen, the calculated load-deflection curve was in good agreement with the measured skeleton curve. This is because the boundary condition was an ideal fixed constraint in the calculation, so that the stiffness of the specimen was large when the calculation was performed. However, the constraint of the specimen in the actual test was relatively weak, so the stiffness was relatively small. When the load exceeded the ultimate load of the specimen, the calculated and measured stiffness of the specimen both started to decay, and the influence of the boundary conditions began to weaken. Overall, the calculated results were in good agreement with the experimental results. 


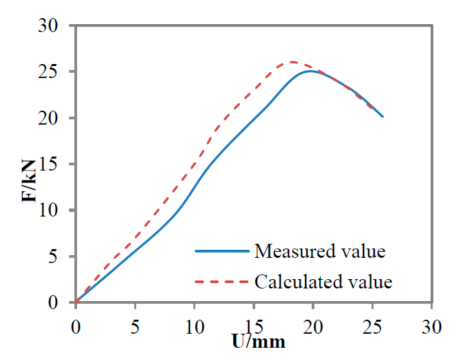

(a)

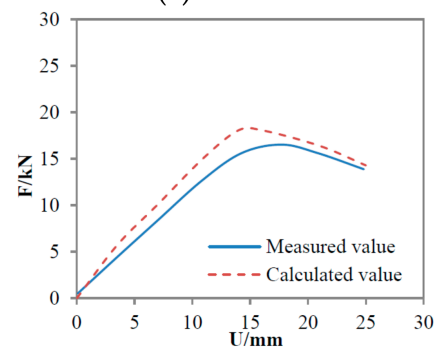

(c)

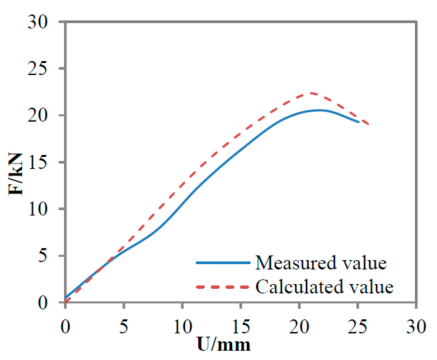

(b)

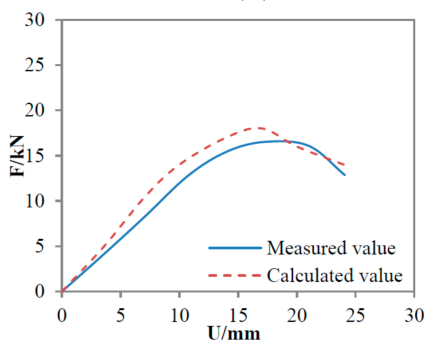

(d)

Figure 19. Comparison of calculated and experimental curves. (a) BD4-40-1; (b) BD4-40-2; (c) BD4-40-3; (d) PD4-40-3.

\subsubsection{Contrastive Analysis of Damage Morphology and Stress Cloud}

In order to analyze the entire damage process of the specimens, test specimen BD4-40-3 was taken as an example to provide a deformation cloud chart of the specimens before and after punching, as shown in Figure 20.

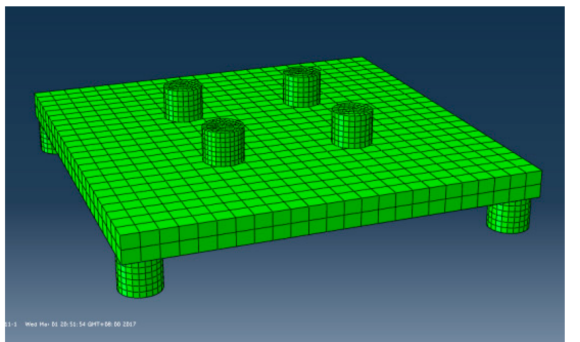

(a)

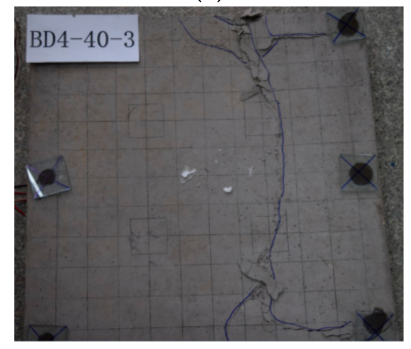

(c)

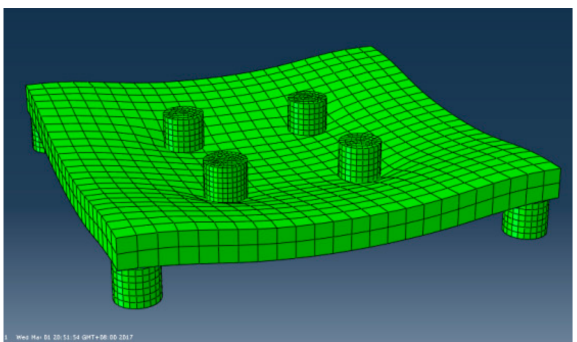

(b)

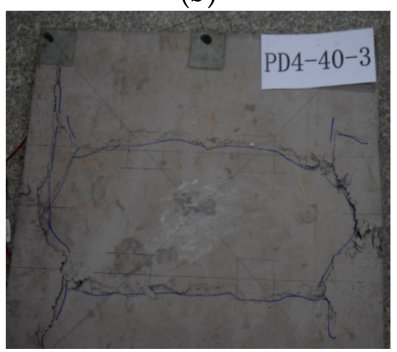

(d)

Figure 20. Simulated deformation and failure modes of specimens. (a) Simulated deformation before loading; (b) Simulated deformation after loading; (c) Failure mode of specimen BD4-40-3; (d) Failure mode of specimen PD4-40-3.

It can be seen from Figure 20b that the deformation of the simulated specimen was more symmetrical when destroyed, and it is obvious that the loading area buckled downward, while the test area buckled downward only to one side (Figure 20c), which is mainly due to the ideal constraint of the specimen in the simulation. At the same time, the initial error (for example, the loading center is not coincident with the 
specimens' center) in the process of simulation was very small. All the while, the comparative specimen PD4-40-3 (Figure 20d) shows that the damage morphology of the model was in good agreement with the experiment.

In order to further analyze the stress changes of concrete and the steel skeleton under different loads, the variations of the principal stress of the concrete and steel skeleton in the compression zone under a cracking load, peak load, and failure load are shown in Figures 21-23.

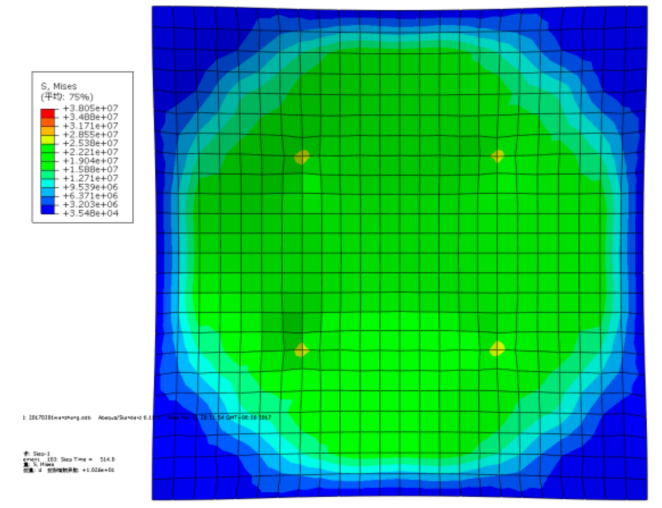

(a)

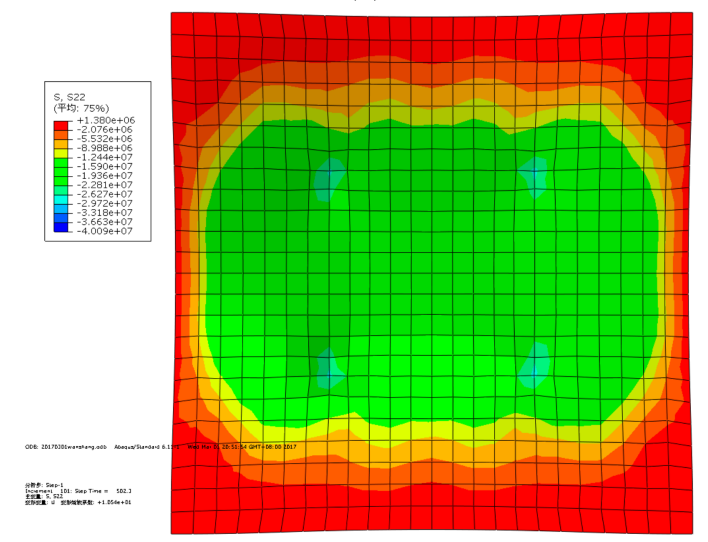

(c)

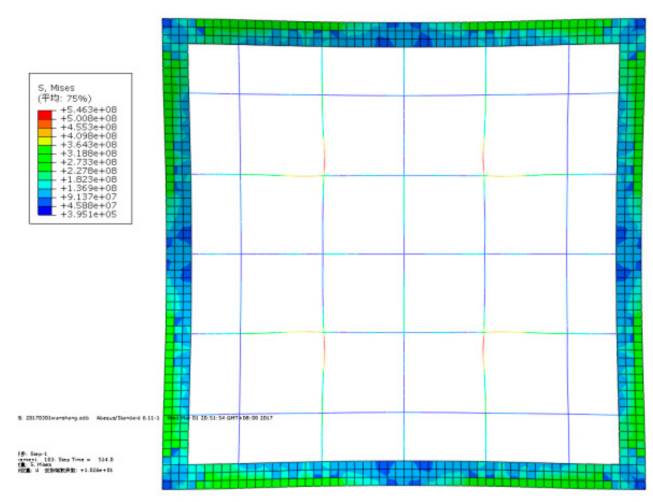

(b)

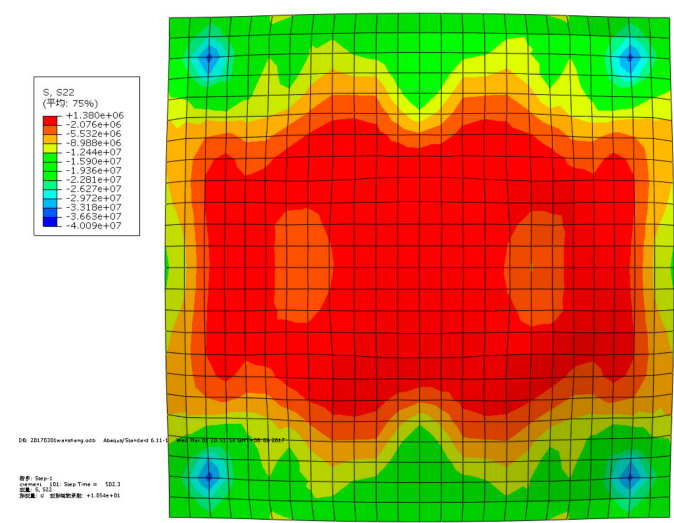

(d)

Figure 21. Mises stress contour figures of concrete and steel skeleton (cracked). (a) Mises stress in the concrete compression zone; (b) Mises stress of the reinforcement skeleton; (c) S22 stress in the concrete compression zone; (d) S22 stress in the concrete tension zone.

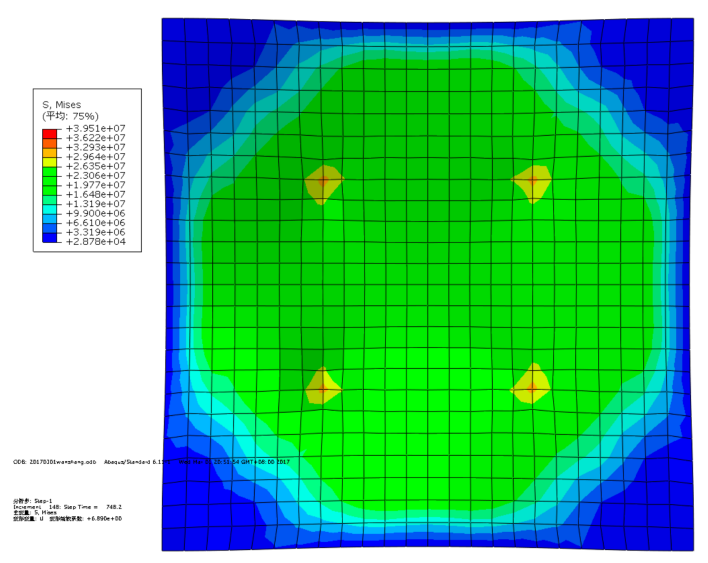

(a)

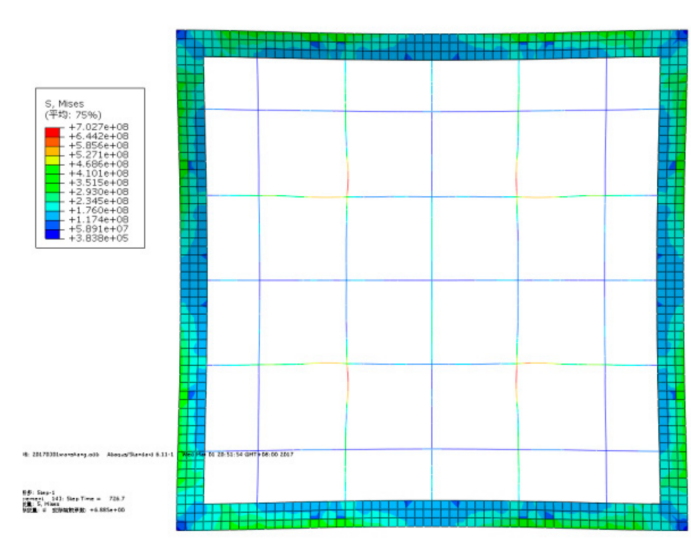

(b)

Figure 22. Cont. 


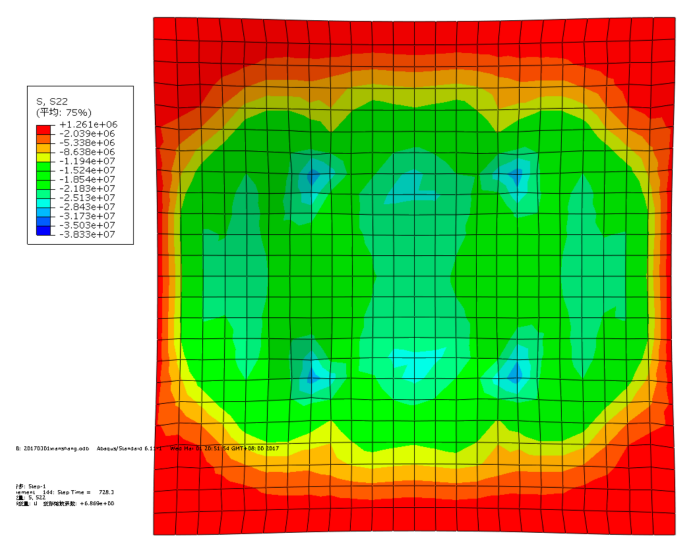

(c)

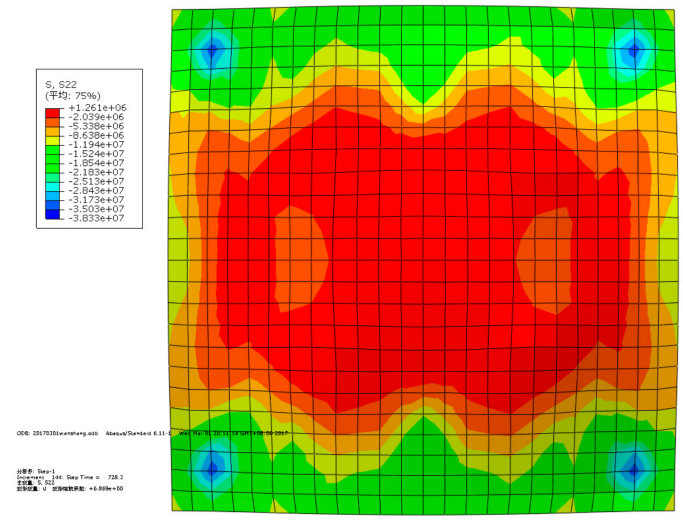

(d)

Figure 22. Mises stress contour figures of concrete and steel skeleton (ultimate). (a) Mises stress in the concrete compression zone; (b) Mises stress of the reinforcement skeleton; (c) S22 stress in the concrete compression zone; (d) S22 stress in the concrete tension zone.

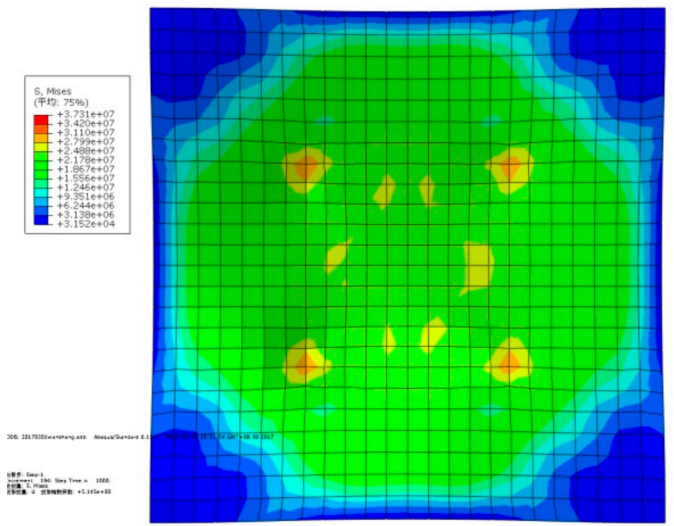

(a)

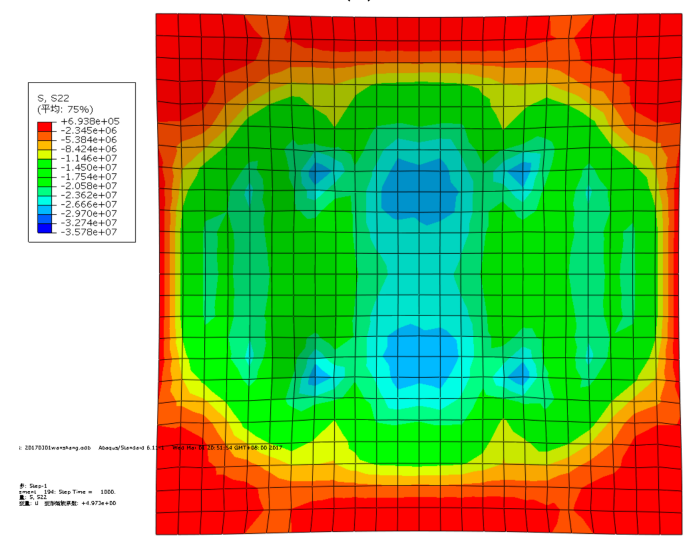

(c)

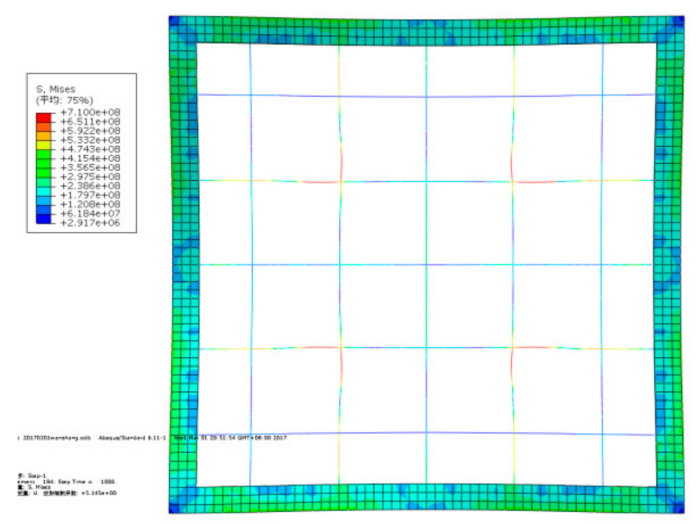

(b)

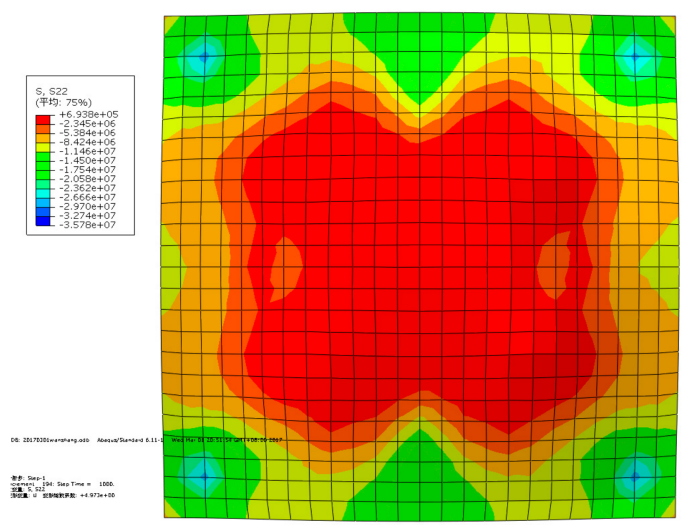

(d)

Figure 23. Mises stress contour figures of concrete and steel skeleton (damaged). (a) Mises stress in the concrete compression zone; (b) Mises stress of the reinforcement skeleton; (c) S22 stress in the concrete compression zone; (d) S22 stress in the concrete tension zone. 
As can be seen from Figure 21 to Figure 23,

(1) When the load was small, the main stress of the concrete in the compression zone of the specimen also was not very large. When the stress in the concrete tension zone reached $1.26-1.38 \mathrm{MPa}$, the concrete in the tension zone cracked, and the concrete stress in the compression zone was between 15.9-19.4 MPa. At this time, the steel's stress reached $546 \mathrm{MPa}$, so the distribution rebar did not yet yield.

(2) When the specimen reached its ultimate load, the compressive strength of the concrete reached its ultimate compressive stress of $39.5 \mathrm{MPa}$, while the distribution rebar did not yet reach its yield strength (702 MPa). This indicates that the failure process of the specimen in the simulation process first has the center of the distribution rebar yielding, followed by essentially crushing of the concrete in the compression zone of the specimen, which is consistent with the experimental results.

(3) When the specimen reached its breaking load, the stress of the concrete in the compression zone was reduced (corresponding to the strain increasing), and the area of the concrete tension zone continued to increase. At this time, the steel rebar entered its strengthening stage, and the stress of the steel bar continued to increase.

\section{Conclusions}

In this paper, the punching performance of 12 wallboards consisting of FAC, RAC, and various types of reinforcement were tested, and the influence of the specimen parameters on the failure mode, bearing capacity and deflection of the specimen was studied. The main conclusions are as follows:

(1) The failure characteristics of ordinary concrete wallboards and recycled concrete wallboards are similar, all of which have a clear punching shear failure, although the recycled concrete samples are more brittle than their new material counterparts, most likely due to the lower elastic modulus of the recycled concrete.

(2) Under the same reinforcement ratio, the ultimate bearing capacity of common concrete wallboard is slightly higher than that of recycled concrete wallboard, with a maximum bearing capacity being $14 \%$ higher, minimum of $1 \%$, and average of $5.8 \%$. These relatively small differences indicate that the concrete material has little influence on the bearing capacity of a specimen.

(3) When the reinforcement ratio is in the range of $0.31-0.42 \%$, each increase of reinforcement ratio by $0.1 \%$ increases the punching ultimate bearing capacity of the wallboards by $2.48 \%$, although the bearing capacity does not correspondingly increases after the reinforcement ratio exceeds a certain limit. In the case of equivalent reinforcement, the bearing capacity of specimens with a larger diameter and spacing are higher by $10.4 \%$ than that of the specimens with smaller diameters and spacing. Although the bearing capacities of the smaller diameter and spacing specimens are slightly lower, the deformation capacities are stronger in the later stage of failure. In actual experiments, late deformation of the specimens should be considered.

(4) The finite element model of a single-row reinforced recycled concrete wallboard was established, and the damage process of the specimen analyzed. The results show that the established finite element model can accurately simulate the failure process and the ultimate failure mode of a specimen, and the calculated load-deflection curve is in good agreement with the experimental curve.

Acknowledgments: The authors would like to acknowledge the financial support from the Key Research and Development Plan of Beijing Municipal Science and Technology Commission (Grant NO. Z161100001216012), China Postdoctoral Science Foundation (Grant NO. 71001015201705) and the Beijing Postdoctoral Science Foundation (Grant NO. Q6001015201702).

Author Contributions: Wenchao Liu performed the experiments and analyzed the data and wrote the paper. Wanlin Cao proposed the topic of this study. Nana Zong, Ruwei Wang, and Lele Ren participated in the manuscript preparation.

Conflicts of Interest: The authors declare that there is no conflict of interests regarding the publication of this paper. 


\section{Abbreviations}

The following abbreviations are used in this manuscript:

$\begin{array}{ll}\text { RAC } & \text { Recycled Aggregates Concrete } \\ \text { RCA } & \text { Recycled Concrete Aggregates } \\ \text { FAC } & \text { Fine Aggregate Concrete } \\ \text { DV } & \text { Different Value } \\ \text { MDV } & \text { Mean Different Value }\end{array}$

\section{References}

1. D'Alessandro, A.; Fabiani, C.; Pisello, A.L.; Ubertini, F.; Materazzi, A.L.; Cotana, F. Innovative concretes for low-carbon constructions: A review. Int. J. Low-Carbon Technol. 2017, 12, 289-309. [CrossRef]

2. Oikonomou, N. Recycled concrete aggregates. Cem. Concr. Compos. 2005, 27, 315-318. [CrossRef]

3. Pacheco-Torgal, F.; Tam, V.W.Y.; Labrincha, J.A.; Ding, Y.; de Brito, J. Handbook of Recycled Concrete and Demolition Waste; Woodhead Publishing: Cambridge, UK, 2013.

4. $\quad$ RT Committee. Specifications for concrete with recycled aggregates. Mater. Struct. 1994, 27, 557-559.

5. Xiao, J.Z.; Li, J.B.; Zhang, C. On relationships between the mechanical properties of recycled aggregate concrete: An overview. Mater. Struct. 2006, 39, 655-664. [CrossRef]

6. Bairagi, N.K.; Vidyadhara, H.S.; Ravande, K. Mix design procedure for recycled aggregate concrete. Constr. Build. Mater. 1990, 4, 188-193. [CrossRef]

7. Kwan, W.H.; Ramli, M.; Kam, K.J.; Sulieman, M.Z. Influence of the amount of recycled coarse aggregate in concrete design and durability properties. Constr. Build. Mater. 2012, 26, 565-573. [CrossRef]

8. Khatib, J.M. Properties of concrete incorporating fine recycled aggregate. Cem. Concr. Res. 2005, 35, 763-769. [CrossRef]

9. Ravindrarajah, R.S.; Tam, C.T. Properties of concrete made with crushed concrete as coarse aggregate. Mag. Concr. Res. 1985, 37, 29-38. [CrossRef]

10. Loo, Y.H.; Tam, C.T.; Ravindrarajah, R.S. Recycled concrete as fine and coarse aggregate in concrete. Mag. Concr. Res. 1987, 39, 214-220.

11. Dosho, Y.; Kikuchi, M.; Akiba, J. Applicability of Recycled Aggregate Concrete for Structural Concrete: Part 6. The Properties of Bending and Shearing on the Recycled Aggregate Concrete. In Summaries of technical papers of Annual Meeting Architectural Institute of Japan; A-1, Materials and construction; Architectural Institute of Japan: Tokyo, Japan, 1998; pp. 739-740.

12. Knaack, A.M.; Kurama, Y.C. Behavior of Reinforced Concrete Beams with Recycled Concrete Coarse Aggregates. J. Struct. Eng. 2015, 141, B4014009. [CrossRef]

13. Han, B.C.; Yun, H.D.; Chung, S.Y. Shear capacity of reinforced concrete beams made with recycled aggregate. ACI Spec. Publ. 2001, 200, 503-516.

14. Han, B.C.; Yun, H.D.; Chung, S.Y. Shear capacity of reinforced concrete beams made with recycled aggregate. In Proceedings of the CANMET/ACI International Conference on Recent Advances in Concrete Technology, Singapore, 29 July-1 August 2001.

15. González-Fonteboa, B.; Martínez-Abella, F. Shear strength of recycled concrete beams. Constr. Build. Mater. 2007, 21, 887-893. [CrossRef]

16. Ajdukiewicz, A.B.; Kliszczewicz, A.T. Comparative tests of beams and columns made of recycled aggregate concrete and natural aggregate concrete. J. Adv. Concr. Technol. 2007, 5, 259-273. [CrossRef]

17. Xiao, J.Z.; Shen, H.B.; Huan, Y.B. Test on Compression Performance of Recycled Concrete Columns. Struct. Eng. 2006, 22, 73-77. (In Chinese)

18. Konno, K.; Sato, Y.; Kakuta, Y.; Ohira, M. Property of recycled concrete column encased by steel tube subjected to axial compression. Trans. Jpn. Concr. Inst. 1997, 19, 231-238.

19. Zhang, J.W.; Cao, W.L.; Dong, H.Y. Experimental study on seismic behavior of mid-rise recycled concrete shear wal with different percentage of aggregate replacement. China Civ. Eng. J. 2010, 55-61. [CrossRef]

20. Cao, W.L.; Liu, Q.; Zhang, J.W. Experimental study on seismic performance of low-rise recycled aggregate concrete shear wall. World Earthq. Eng. 2009, 25, 1-5. 
21. Zhang, J.W.; Cao, W.L.; Zhu, H.; Dong, H.Y. Study on aseismic behavior of mid-rise recycled recycled aggregate concrete concrete shear wall. Eng. Mech. 2010, 27 (Suppl. I), 270-274. (In Chinese)

22. Zhou, Z.Y.; Cao, W. Experimental study on seismic performance of low-rise recycled aggregate concrete shear wall with single-layer reinforcement. Adv. Struct. Eng. 2017, 20, 1493-1511. [CrossRef]

23. Liu, W.C.; Cao, W.L.; Zhang, J.W. Seismic Performance of Composite Shear Walls Constructed Using Recycled Aggregate Concrete and Different Expandable Polystyrene Configurations. Materials 2016, 9, 148. [CrossRef] [PubMed]

24. Talbot, A.N. Reinforced Concrete Wall Footings and Column Footings; And in Charge of Theoretical \& Applied Mechanics; University of Illinois: Champaign, IL, USA, 1925.

25. Elstner, R.C.; Eivind, H. Shearing strength of reinforced concrete slabs. ACI Struct. J. 1956, 53, 29.

26. Zheng, Z.Q.; Ouyang, C.S. Punching strength of reinforced concrete circular slabs. J. Build. Struct. 1985, 6, 14-23.

27. Xiao, J.Z.; Zhou, Z.J.; Tawana, M.M. Test on punching behavior of recycled aggregate concrete slabs. J. TongJi Univ. Nat. Sci. 2015, 43, 41-46.

28. Hassan, M.; Ahmed, E.A.; Benmokrane, B. Punching-shear design equation for two-way concrete slabs reinforced with FRP bars and stirrups. Constr. Build. Mater. 2014, 66, 522-532. [CrossRef]

29. Cao, W.L.; Zhang, J.; Dong, H.Y. Experimental research on flexural performance of high strength recycled aggregate concrete slabs with steel bar truss. J. Build. Struct. 2014, 35, 31-38.

30. Zhou, J.H.; Wang, X.B.; Yu, T.H. Mechanic Behavior Test on Recycled Concrete Simply-Supported Rectangular Slabs. J. Shenyang Jianzhu Univ. Nat. Sci. 2008, 24, 411-415. (In Chinese)

31. China Standards Publication. Recycled Coarse Aggregate for Concrete; GB/T25177-2010; Standard Press of China: Beijing, China, 2011. (In Chinese)

32. China Standards Publication. Metallic Materials-Tensile Testing at Ambient Temperature; GB/T 228-2002; Standard Press of China: Beijing, China, 2003. (In Chinese)

33. China Standards Publication. Code for Construction of Concrete Structures; GB 50010-2010; Standard Press of China: Beijing, China, 2011. (In Chinese)

34. Guo, Z.H. Strength and Constitutive Relation of Concrete; China Architecture Industry Press: Beijing, China, 2004. (In Chinese)

35. Shi, Y.P. Detailed Annotation of Abaqus Finite Element Analysis; Mechanical Industry Press: Beijing, China, 2005. (In Chinese)

36. Xiao, J.Z. Experimental investigation on complete stress-strain curve of recycled concrete under uniaxial loading. J. TongJi Univ. Nat. Sci. 2007, 35, 1445-1449.

37. Guo, Z.H.; Shi, X.D. Reinforced Concrete Theory and Analyze; Press of Tsinghua University: Beijing, China, 2003. (In Chinese)

38. Hibbitt, Karlsson \& Sorensen. ABAQUS/Standard User's Manual, version 6.4; Hibbitt, Karlsson \& Sorensen Inc.: Rawtucket, RI, USA, 2004.

(C) 2018 by the authors. Licensee MDPI, Basel, Switzerland. This article is an open access article distributed under the terms and conditions of the Creative Commons Attribution (CC BY) license (http:// creativecommons.org/licenses/by/4.0/). 